\title{
Mixed Flow Reactor Experiments and Modeling of Sulfuric Acid Neutralization in Lube Oil for Large Two-Stroke Diesel Engines
}

Lejre, Kasper H.; Glarborg, Peter; Christensen, Henrik; Mayer, Stefan; Kiil, Søren

Published in:

Industrial \& Engineering Chemistry Research

Link to article, DOI:

10.1021/acs.iecr.8b05808

Publication date:

2019

Document Version

Peer reviewed version

Link back to DTU Orbit

Citation (APA):

Lejre, K. H., Glarborg, P., Christensen, H., Mayer, S., \& Kiil, S. (2019). Mixed Flow Reactor Experiments and Modeling of Sulfuric Acid Neutralization in Lube Oil for Large Two-Stroke Diesel Engines. Industrial \& Engineering Chemistry Research, 58(1), 138-155. https://doi.org/10.1021/acs.iecr.8b05808

\section{General rights}

Copyright and moral rights for the publications made accessible in the public portal are retained by the authors and/or other copyright owners and it is a condition of accessing publications that users recognise and abide by the legal requirements associated with these rights.

- Users may download and print one copy of any publication from the public portal for the purpose of private study or research.

- You may not further distribute the material or use it for any profit-making activity or commercial gain

- You may freely distribute the URL identifying the publication in the public portal 


\section{Kinetics, Catalysis, and Reaction Engineering}

\section{Mixed Flow Reactor Experiments and Modeling of Sulfuric Acid Neutralization in Lube Oil for Large Two-Stroke Diesel Engines}

Kasper Hartvig Lejre, Peter Glarborg, Henrik Christensen, Stefan Mayer, and Søren Kiil Ind. Eng. Chem. Res., Just Accepted Manuscript • DOI: 10.1021/acs.iecr.8b05808 • Publication Date (Web): 06 Dec 2018

Downloaded from http://pubs.acs.org on December 6, 2018

\section{Just Accepted}

"Just Accepted" manuscripts have been peer-reviewed and accepted for publication. They are posted online prior to technical editing, formatting for publication and author proofing. The American Chemical Society provides "Just Accepted" as a service to the research community to expedite the dissemination of scientific material as soon as possible after acceptance. "Just Accepted" manuscripts appear in full in PDF format accompanied by an HTML abstract. "Just Accepted" manuscripts have been fully peer reviewed, but should not be considered the official version of record. They are citable by the Digital Object Identifier (DOI®). "Just Accepted" is an optional service offered to authors. Therefore, the "Just Accepted" Web site may not include all articles that will be published in the journal. After a manuscript is technically edited and formatted, it will be removed from the "Just Accepted" Web site and published as an ASAP article. Note that technical editing may introduce minor changes to the manuscript text and/or graphics which could affect content, and all legal disclaimers and ethical guidelines that apply to the journal pertain. ACS cannot be held responsible for errors or consequences arising from the use of information contained in these "Just Accepted" manuscripts. 


\title{
Mixed Flow Reactor Experiments and Modeling of Sulfuric
}

\section{Acid Neutralization in Lube Oil for Large Two-Stroke Diesel Engines}

Kasper H. Lejre, ${ }^{a}$ Peter Glarborg, ${ }^{a}$ Henrik Christensen, ${ }^{b}$ Stefan Mayer, ${ }^{b}$ and Søren Kiil ${ }^{*}, a$

${ }^{\mathrm{a} D e p a r t m e n t ~ o f ~ C h e m i c a l ~ a n d ~ B i o c h e m i c a l ~ E n g i n e e r i n g, ~ T e c h n i c a l ~ U n i v e r s i t y ~ o f ~ D e n m a r k, ~ S ø l t o f t s ~ P l a d s ~ 229, ~}$ 2800 Kgs. Lyngby, Denmark

${ }^{\mathrm{b}}$ MAN Energy Solutions, Teglholmsgade 41, 2450 Copenhagen SV, Denmark

\begin{abstract}
Lubrication oil for marine diesel engines contains additives in the form of $\mathrm{CaCO}_{3}$-based reverse micelles, which can neutralize condensing $\mathrm{H}_{2} \mathrm{SO}_{4}$, and thereby limit uncontrolled corrosive wear of the piston rings and cylinder liner. In the present work, the neutralization mechanism was studied experimentally and through modeling. Using a mixed flow reactor (MFR), the rate of the acid-base reaction was measured as a function of relevant process parameters. In addition, the competition between $\mathrm{CaCO}_{3}$ reverse micelles and $\mathrm{NaOH}$ droplets for a reaction with $\mathrm{H}_{2} \mathrm{SO}_{4}$ droplets in a lube oil emulsion was explored in a batch reactor. For the residence times investigated, the results show that $\mathrm{CaCO}_{3}$ conversion is significantly reduced when reaching a critically low $\mathrm{Ca} / \mathrm{S}$ ratio. Furthermore, a mathematical model for the neutralization of $\mathrm{H}_{2} \mathrm{SO}_{4}$ droplets by $\mathrm{CaCO}_{3}$ reverse micelles in lube oil under well-mixed conditions was developed. Both the experimental data and simulations support previous results suggesting that the limiting step in the neutralization mechanism is adsorption of reverse micelles onto the much larger $\mathrm{H}_{2} \mathrm{SO}_{4}$ droplets. Using the video-microscopy experiments of $\mathrm{Fu}$ et al.
\end{abstract}


[Tribol. Lett. 2006, 22 (3), 221-225], it was possible to estimate kinetic parameters for the adsorption-controlled reaction. The model was used to predict conversion of $\mathrm{H}_{2} \mathrm{SO}_{4}$ in a lube oil film at the cylinder liner surface for conditions relevant for a full-scale application. Calculations indicated that $\mathrm{H}_{2} \mathrm{SO}_{4}$ may reach the liner surface regardless of how well-wetted the surface is.

\section{Introduction}

As a result of the economic crisis of 2008 and the abundance of ships in the shipping market, the slow-steaming operation principle for large two-stroke diesel engines emerged as a measure for increasing fuel efficiency. Use of slow-steaming, combined with new engine designs and tunings for further fuel savings, led to increased operating cylinder pressure and lower liner surface temperature. ${ }^{1}$ These changes in operating conditions result in increased water and acid condensation on the cylinder lubrication (lube) oil film on the cast iron liner surfaces, ${ }^{2-4}$ promoting a combination of corrosion and wear (cold corrosion) of the cylinder liners and piston rings and significantly reducing their lifetime. ${ }^{1,5-7}$ The condensing acid is mainly aqueous sulfuric acid $\left(\mathrm{H}_{2} \mathrm{SO}_{4}\right)$, originating from oxidation of the sulfur-rich fuel oil burned in marine diesel engines. ${ }^{8,9}$ Commercial lube oils are typically formulated with calcium carbonate $\left(\mathrm{CaCO}_{3}\right)$ overbased detergent additives, present as nanometersized reverse micelles, which neutralize condensed $\mathrm{H}_{2} \mathrm{SO}_{4}$ in the lube oil film. ${ }^{10-16}$ To counteract the increased condensation rate of $\mathrm{H}_{2} \mathrm{SO}_{4}$, it is necessary to increase the amount of $\mathrm{CaCO}_{3}$ being fed to the cylinder liners, which is preferably done by increasing the concentration of $\mathrm{CaCO}_{3}$ in the lube oil, rather than the oil feed rate. ${ }^{1,2,17}$ Under-lubrication may result in cold corrosion, which can occur within hours, ${ }^{18}$ while over-lubrication is cost-intensive and may lead to bore-polish (creating a mirror-like cylinder liner surface), which prevents formation of a coherent lube oil film. Both may eventually result in scuffing (direct metal to metal contact). ${ }^{6,19}$ Actually, a certain degree of controlled corrosion is beneficial; if the cylinder liners are a little rough, they can better maintain a protective lube oil film. ${ }^{6,11}$ Therefore, to limit and control cold corrosion in engines, the lubrication strategy must be optimized. This is a challenge, especially when trying to set up general 
recommendations. ${ }^{3}$ The situation gets even more complicated when switching fuel during service to comply with the new stricter sulfur regulations. ${ }^{18}$ An understanding of what affects and limits the reaction between the condensing $\mathrm{H}_{2} \mathrm{SO}_{4}$ and the neutralizing additives, $\mathrm{CaCO}_{3}$ reverse micelles, in the lube oil can provide greater insight into how to optimize the lubrication strategy to limit cold corrosion.

The reaction between (sulfuric) acid droplets and $\mathrm{CaCO}_{3}$ reverse micelles in lube oil has been investigated in laboratory experiments over a wide range of conditions. Data in batch mode were obtained using a videomicroscopy technique, ${ }^{20-29}$ a stopped-flow method, ${ }^{30-32}$ and by monitoring the $\mathrm{CO}_{2}$ formed. ${ }^{33-36}$ The videomicroscopy experiments employed placing of single acid droplets (70-200 $\mu \mathrm{m}$ in diameter) in a batch of lube oil, followed by measuring the subsequent shrinkage of the acid droplets. These studies indicate that the controlling step of the neutralization reaction is adsorption of a reverse micelle onto the acid droplet. In the capillary video-microscopy technique investigations, $\mathrm{CaCO}_{3}$ reverse micelles were present in great excess on a molar basis compared to $\mathrm{H}_{2} \mathrm{SO}_{4},{ }^{25}$ while an excess of concentrated $\mathrm{H}_{2} \mathrm{SO}_{4}$ was used in the closed vessel experiments. $^{35,37}$

Within an engine, the reaction taking place in the lube oil occurs in a system with continuous feeding of fresh lube oil and condensation of $\mathrm{H}_{2} \mathrm{SO}_{4}$, followed by the removal of lube oil to the drain. Presumably, the lube oil film is effectively mixed by the motion of the piston rings. In order to provide a better approximation of the reaction conditions in the lube oil at the cylinder liners in a full-scale marine diesel engine, Lejre et al. ${ }^{38}$ used a mixed flow reactor (MFR) to study the reaction. They found that a certain intensity of stirring was required to initiate and maintain the reaction. Upon formation and stabilization of the $\mathrm{H}_{2} \mathrm{SO}_{4}$ into $\mu \mathrm{m}$-sized droplets by the excess emulsifier molecules, a fast reaction occurred, as indicated by a sudden color change of the oil due to the formation of $\mathrm{CO}_{2}$. The $\mathrm{H}_{2} \mathrm{SO}_{4}-\mathrm{CaCO}_{3}$ reaction at steady-state was significantly reduced when a critically low $\mathrm{Ca} / \mathrm{S}$ molar ratio was reached, in agreement with the observations of Roman. ${ }^{35}$ Lejre et al. suggested that macromixing or micelle adsorption/desorption could be the controlling step under their conditions. 
Models for the neutralization reaction are scarce. Schramm et al. ${ }^{39}$ and Van Helden et al. ${ }^{40,41}$ modeled cylinder liner corrosion, assuming that the neutralization of $\mathrm{H}_{2} \mathrm{SO}_{4}$ by $\mathrm{CaCO}_{3}$ reverse micelles was acid diffusioncontrolled. However, this assumption is contradicted by more recent investigations. Hone et al. ${ }^{31}$ determined an activation energy, $E_{a}$, for the reaction of $54 \pm 2 \mathrm{~kJ} \mathrm{~mol}^{-1}$, concluding that the neutralization reaction is not diffusion-controlled, because diffusion-controlled reactions usually have activation energies of less than circa $20 \mathrm{~kJ} \mathrm{~mol}^{-1}$. The work of Hone et al. is supported by data from Fu et al., ${ }^{24}$ who reported a 1000-fold increase in the neutralization rate when increasing the temperature from 25 to $170{ }^{\circ} \mathrm{C}$, which corresponds to an activation energy of $52.8 \mathrm{~kJ} \mathrm{~mol}^{-1}$.

The scope of the present work is to identify the rate-influencing steps (potentially a single rate-controlling one) in the neutralization reaction between $\mathrm{H}_{2} \mathrm{SO}_{4}$ droplets and $\mathrm{CaCO}_{3}$ reverse micelles and to set up a mathematical model for the reaction system in a mixed flow reactor. The first part investigates the mechanism of the reaction and identifies the possible rate-limiting steps. Batch reactor experiments are conducted, comparing the reaction rate of $\mathrm{CaCO}_{3}$ reverse micelles and $\mathrm{NaOH}$ droplets, respectively, with $\mathrm{H}_{2} \mathrm{SO}_{4}$ in a lube oil, in order to assess the possibility of the reaction between $\mathrm{CaCO}_{3}$ and $\mathrm{H}_{2} \mathrm{SO}_{4}$ being diffusion-controlled. Next, a mathematical model for the reaction system in a mixed flow reactor is set up and kinetic data for the reaction are extracted from the video-microscopy experiments performed by $\mathrm{Fu}$ et al. $^{24}$ Simulations are validated against experimental data from the MFR experiments in our previous ${ }^{38}$ and present work. Finally, the $\mathrm{H}_{2} \mathrm{SO}_{4}-\mathrm{CaCO}_{3}$ neutralization reaction is explored under conditions representative of a marine diesel engine.

\section{Experimental work}

Experiments involving the reaction between $\mathrm{H}_{2} \mathrm{SO}_{4}$ droplets and $\mathrm{CaCO}_{3}$-containing micelles in a lube oil were conducted in a reactor that could be operated both in batch and mixed-flow mode. The experimental procedure is described in detail in our previous work ${ }^{38}$ and is therefore only touched upon briefly here. 


\subsection{Materials}

The commercial lube oil used for the experiments was from Infineum and had a stated base number value (BN) of 100. The BN is defined as the quantity of acid, expressed in terms of the equivalent number of milligrams of $\mathrm{KOH}$ required to neutralize all alkaline constituents in a one gram sample. ${ }^{42} \mathrm{The}_{2} \mathrm{SO}_{4}$ was obtained from Sigma-Aldrich with a concentration of 95-98 wt.\%. The $\mathrm{NaOH}$ solution used was $50 \mathrm{wt} . \%$ in water and also from Sigma-Aldrich.

\subsection{Reactor}

Operation in mixed flow reactor (MFR) mode is described elsewhere. ${ }^{38}$ In short, $\mathrm{H}_{2} \mathrm{SO}_{4}(\mathrm{aq}$ ) and lube oil were dosed separately to the reactor and mixed by a motor-driven stirrer. In MFR mode, the feeding was continuous and the level of oil emulsion in the reactor was kept constant by an outlet pump. By taking measurements of the inlet flow rate and reactor volume, the residence time in the reactor could then be calculated.

The reactor was also operated in batch mode to study the competition between $\mathrm{NaOH}$ and $\mathrm{CaCO}_{3}$ reacting in the lube oil. Specific amounts of lube oil and $\mathrm{NaOH}$ were mixed for 30 minutes at a maximum stirrer speed of 1200 rpm in order to ensure solubilization of the $\mathrm{NaOH}$ droplets into the lube oil. Maintaining $1200 \mathrm{rpm}$, concentrated $\mathrm{H}_{2} \mathrm{SO}_{4}$ was added dropwise by use of a syringe into the well-mixed lube oil emulsion, thus keeping a constant lube oil temperature of around $50{ }^{\circ} \mathrm{C}$. A molar ratio between $\mathrm{NaOH}$ and $\mathrm{CaCO}_{3}$ of 2 was chosen since $\mathrm{NaOH}$ and $\mathrm{H}_{2} \mathrm{SO}_{4}$ reacts 2:1, whereas $\mathrm{CaCO}_{3}$ and $\mathrm{H}_{2} \mathrm{SO}_{4}$ reacts 1:1. $\mathrm{CaCO}_{3}-\mathrm{H}_{2} \mathrm{SO}_{4}(\mathrm{Ca} / \mathrm{S})$ molar ratios of 0.8 and 1.0 were also investigated. After the addition of $\mathrm{H}_{2} \mathrm{SO}_{4}$, mixing continued for 20 minutes to ensure complete conversion of $\mathrm{H}_{2} \mathrm{SO}_{4}$ by reaction with $\mathrm{CaCO}_{3}$ reverse micelles and/or $\mathrm{NaOH}$ droplets.

\subsection{Analysis method}

The oil samples were analyzed by FTIR, and a calibration curve was used to convert the peak height of the $\mathrm{CaCO}_{3}$ peak to the base number in the lube oil sample. ${ }^{38}$ Selected infrared spectra (wavenumber range from 900 
to $1700 \mathrm{~cm}^{-1}$ ) are presented in Figure 1 for four different contents of BN in the lube oil after reaction with added $\mathrm{H}_{2} \mathrm{SO}_{4}$. The $\mathrm{CaCO}_{3}$ concentrations were in the range of between 98.6 $\mathrm{BN}$ (a fresh lube oil) down to $21.5 \mathrm{BN}$ (around $80 \%$ conversion of the $\mathrm{CaCO}_{3}$ ). When increasing the amount of $\mathrm{H}_{2} \mathrm{SO}_{4}$ added, more $\mathrm{CaCO}_{3}$ is converted. This is shown as a decrease for the $\mathrm{CaCO}_{3}$ band in Figure 1, and vice versa for the $\mathrm{CaSO}_{4}$ band. For the MFR experiments, an outlet sample was sampled at steady state and analyzed immediately to estimate the conversion of $\mathrm{CaCO}_{3}$ (this conversion is denoted as Fast Analysis). Afterwards, the sample was stirred to ensure complete conversion of remaining $\mathrm{H}_{2} \mathrm{SO}_{4}$, if any. The sample was then analyzed again by FTIR and denoted Complete Conversion Analysis. Comparing the two conversions revealed if complete conversion of the added $\mathrm{H}_{2} \mathrm{SO}_{4}$ was achieved in the MFR within the specified residence time.

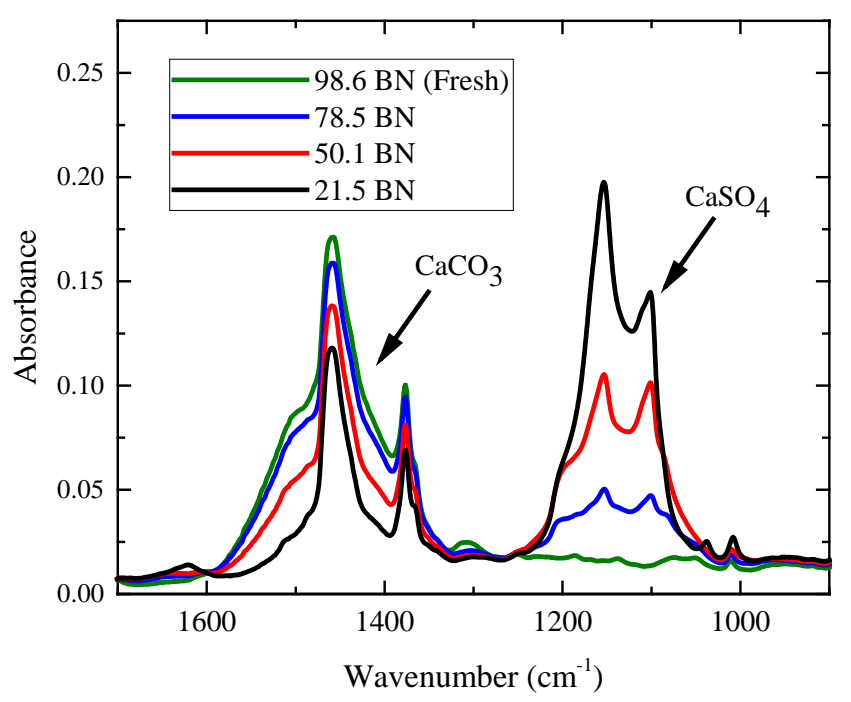

Figure 1. Selected segment of infrared spectra showing the $\mathrm{CaCO}_{3}$ and $\mathrm{CaSO}_{4}$ peaks of four different lube oil blends with different amounts of added $\mathrm{H}_{2} \mathrm{SO}_{4}$, giving $\mathrm{CaCO}_{3}$ concentrations in the range 98.6-21.5 BN. When more $\mathrm{H}_{2} \mathrm{SO}_{4}$ is added, the $\mathrm{CaCO}_{3}$ peak decreases and the $\mathrm{CaSO}_{4}$ increases. The spectrum of the 98.6 $\mathrm{BN}$ lube oil is a fresh lube oil without the addition of $\mathrm{H}_{2} \mathrm{SO}_{4}$.

The reacted lube oil from the batch reactor experiments was analyzed by FTIR after complete conversion of the added $\mathrm{H}_{2} \mathrm{SO}_{4}$. A two-point calibration curve was constructed, adding 50 wt.\% $\mathrm{NaOH}$ to the lube oil sample, 
prior to analysis on the FTIR, in order to match the $\mathrm{NaOH} / \mathrm{CaCO}_{3}$ molar ratio used in the batch reactor experiments. It was then possible to estimate the conversion of $\mathrm{CaCO}_{3}$ in the lube oil and consequently the conversion of $\mathrm{NaOH}$ by the added $\mathrm{H}_{2} \mathrm{SO}_{4}$.

\section{Neutralization mechanism and rate-limiting steps}

The reaction between acid $\left(\mathrm{H}_{2} \mathrm{SO}_{4}\right)$ droplets and alkaline $\left(\mathrm{CaCO}_{3}\right)$ reverse micelles $(\mathrm{RM})$ is thought to proceed through the mechanism presented in Figure 2. ${ }^{20,21}$
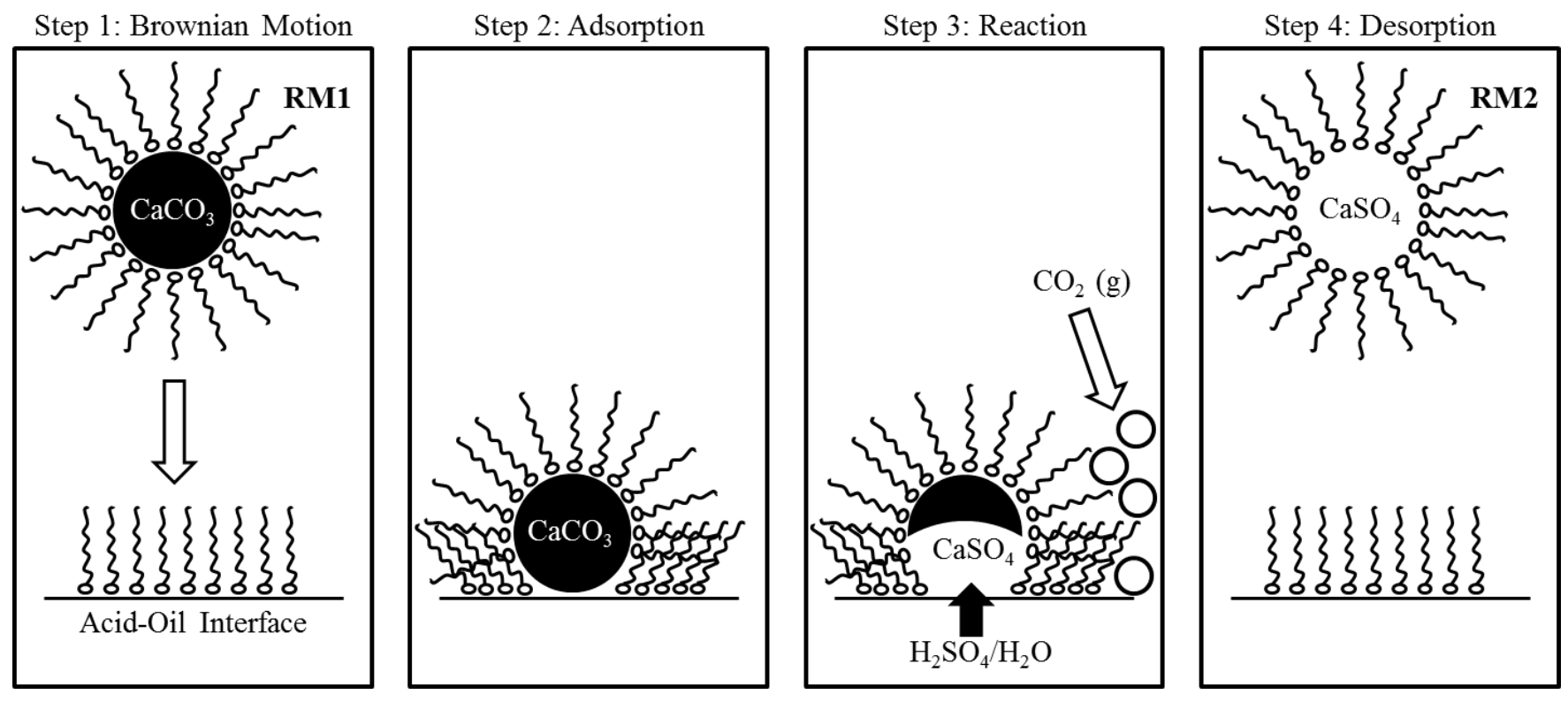

Figure 2. Neutralization mechanism between an acid droplet and $\mathrm{CaCO}_{3}$ reverse micelle (adapted from Wu et al. $\left.{ }^{21}\right)$.

The first step (Step 1 in Figure 2) is a collision between the reverse micelle (RM1) and the acid droplet interface by Brownian motion. A successful collision leads to adsorption of the reverse micelle to the acid interface (Step 2 in Figure 2). Next, a channel forms and $\mathrm{H}_{2} \mathrm{SO}_{4}$ and $\mathrm{CaCO}_{3}$ react by the transferring of acid into the reverse micelles (Step 3 in Figure 2). After reaction, the reaction products are located in the reverse micelle (now called RM2), which desorbs from the acid droplet and back into the bulk oil (Step 4 in Figure 2). However, different 
locations for the reaction products has been noted in the literature. ${ }^{21,25,31,34} \mathrm{Fu}$ et al. ${ }^{25}$ observed four different reaction behaviors in different lube oil formulations within a temperature range $25-170{ }^{\circ} \mathrm{C}$, and attributed these differences to different lube oil formulations, temperatures, and overbased detergents. The observed reaction behaviors were explained by a strong/weak-stick collision mechanism in which the neutralization rate is enhanced by formulating lube oils with a high frequency of strong-stick collisions. Based on these studies and the work by Lejre et al., ${ }^{38}$ possible rate-limiting steps in the neutralization mechanism between $\mathrm{H}_{2} \mathrm{SO}_{4}$ and $\mathrm{CaCO}_{3}$ reverse micelles in lube oil formulations include: micelle diffusion, micelle adsorption, surface reaction, micelle desorption, and macromixing. For micelle diffusion to be rate-limiting, the rate by which the micelles diffuse must be comparable to the overall rate of reaction. If the limiting step is adsorption of a micelle onto a $\mathrm{H}_{2} \mathrm{SO}_{4}$ droplet, the reaction is controlled by the occurrence of a successful "sticky" collision. This is in contrast to a diffusion-controlled reaction, where the reaction is taking place at every collision. If the $\mathrm{CaCO}_{3}$ reverse micelles have a strong adhesion to the $\mathrm{H}_{2} \mathrm{SO}_{4}$ droplet surface, occupying the surface of the droplet and preventing unreacted $\mathrm{CaCO}_{3}$ reverse micelles to adsorb, desorption may become the rate-limiting step in the neutralization mechanism. If the surface reaction is the rate-controlling step, the reaction rate will be limited by the rate of surface reaction between $\mathrm{H}_{2} \mathrm{SO}_{4}$ and $\mathrm{CaCO}_{3}$. However, the reaction is an acid-base reaction occurring irreversibly. Due to the small size of the $\mathrm{CaCO}_{3}$ particles in lube oil (8-18 nanometers in diameter ${ }^{22}$ ), and the fact that the reaction rate increases with decreasing $\mathrm{CaCO}_{3}$ particle size in acid, ${ }^{43}$ it is presumed that the surface reaction between $\mathrm{CaCO}_{3}$ and $\mathrm{H}_{2} \mathrm{SO}_{4}$ happens instantaneously, and the surface reaction is therefore not the ratelimiting step in the neutralization mechanism. ${ }^{21}$ Finally, the reaction can also be controlled by the rate with which $\mathrm{H}_{2} \mathrm{SO}_{4}$ droplets and $\mathrm{CaCO}_{3}$ reverse micelles are mixed in the reactor. In the following, possible ratelimiting steps are investigated and evaluated from batch reactor and mixed flow reactor experiments.

\subsection{Batch reactor experiments - diffusion limitation}


To evaluate whether or not the $\mathrm{CaCO}_{3}-\mathrm{H}_{2} \mathrm{SO}_{4}$ reaction is diffusion-controlled, the relative rates of the $\mathrm{H}_{2} \mathrm{SO}_{4}$ $\mathrm{CaCO}_{3}$ and $\mathrm{H}_{2} \mathrm{SO}_{4}-\mathrm{NaOH}$ reactions were investigated in batch reactor experiments:

$$
\begin{aligned}
& \mathrm{H}_{2} \mathrm{SO}_{4}(a q)+\mathrm{CaCO}_{3}(s) \rightarrow \mathrm{CaSO}_{4}(s)+\mathrm{CO}_{2}(g)+\mathrm{H}_{2} \mathrm{O}(l) \\
& \mathrm{H}_{2} \mathrm{SO}_{4}(a q)+2 \mathrm{NaOH}(a q) \rightarrow \mathrm{Na}_{2} \mathrm{SO}_{4}(s)+2 \mathrm{H}_{2} \mathrm{O}(l)
\end{aligned}
$$

The reaction between $\mathrm{H}_{2} \mathrm{SO}_{4}$ and $\mathrm{NaOH}$ is diffusion-controlled, ${ }^{44}$ as it can be considered instantaneous upon contact. If the reaction between $\mathrm{CaCO}_{3}$ and $\mathrm{H}_{2} \mathrm{SO}_{4}$ is also diffusion-controlled, it would be expected that $\mathrm{H}_{2} \mathrm{SO}_{4}$ would react to a larger degree with $\mathrm{CaCO}_{3}$ than with $\mathrm{NaOH}$. A smaller particle size leads to a higher diffusion coefficient, thereby increasing the diffusion-controlled reaction rate on a molar basis, ${ }^{44}$ and the $\mathrm{NaOH}$ droplets are much larger than the nanometer-sized micelles. In the experiments, the $\mathrm{NaOH}$ was solubilized into the lube oil by the excess dispersant and detergent molecules already present in the oil. ${ }^{35}$ Common emulsions have a particle size distribution with a radius in the range of $1-10 \mu \mathrm{m},{ }^{45}$ which may be a representative size range for the emulsified $\mathrm{NaOH}$ droplets in the lube oil.

It is not expected that the controlling step for the $\mathrm{NaOH}-\mathrm{H}_{2} \mathrm{SO}_{4}$ reaction would be changed when $\mathrm{NaOH}$ is solubilized into the lube oil emulsion. When the equal-sized $\mathrm{H}_{2} \mathrm{SO}_{4}$ and $\mathrm{NaOH}$ droplets (micrometer) collide, they are much larger than the nanometer-sized surfactants that may surround the droplets. It is therefore presumed that the surfactants do not constitute any hindrance for the $\mathrm{NaOH}-\mathrm{H}_{2} \mathrm{SO}_{4}$ reaction. The reaction is further enhanced by the high stirring intensity used.

The batch reactor experiments were performed with a fixed molar ratio between $\mathrm{NaOH}$ and $\mathrm{CaCO}_{3}$ of 2 , corresponding to the stoichiometry of the reactions with $\mathrm{H}_{2} \mathrm{SO}_{4}$. Care was taken to provide equal mixing conditions for the $\mathrm{NaOH}$ and $\mathrm{CaCO}_{3}$ to react with the added $\mathrm{H}_{2} \mathrm{SO}_{4}$ in the well-mixed reactor. Upon mixing of the lube oil and $\mathrm{NaOH}$ solution, concentrated $\mathrm{H}_{2} \mathrm{SO}_{4}$ was added dropwise. Two different $\mathrm{Ca} / \mathrm{S}$ molar ratios were then investigated. At a $\mathrm{Ca} / \mathrm{S}=1$, the neutralization ability of $\mathrm{H}_{2} \mathrm{SO}_{4}$ is $100 \%$, meaning that the added $\mathrm{H}_{2} \mathrm{SO}_{4}$ has the ability to either convert all the $\mathrm{CaCO}_{3}$, all the $\mathrm{NaOH}$, or a mixture thereof. If all of the $\mathrm{H}_{2} \mathrm{SO}_{4}$ reacts first with the $\mathrm{CaCO}_{3}, 100 \%$ conversion of the $\mathrm{CaCO}_{3}$ and $0 \%$ conversion of the $\mathrm{NaOH}$ would be found at complete conversion of the $\mathrm{H}_{2} \mathrm{SO}_{4}$. At $\mathrm{Ca} / \mathrm{S}=0.8$, the $\mathrm{H}_{2} \mathrm{SO}_{4}$ is in excess compared to the $\mathrm{CaCO}_{3}$ in the lube oil. 
Moreover, if all of the $\mathrm{CaCO}_{3}$ is converted first, $25 \%$ conversion of the $\mathrm{NaOH}$ would be found at complete conversion of the $\mathrm{H}_{2} \mathrm{SO}_{4}$. The percentage conversions of $\mathrm{CaCO}_{3}$ and $\mathrm{NaOH}$ with $\mathrm{H}_{2} \mathrm{SO}_{4}$ from the batch reactor experiments are shown in Figure 3.

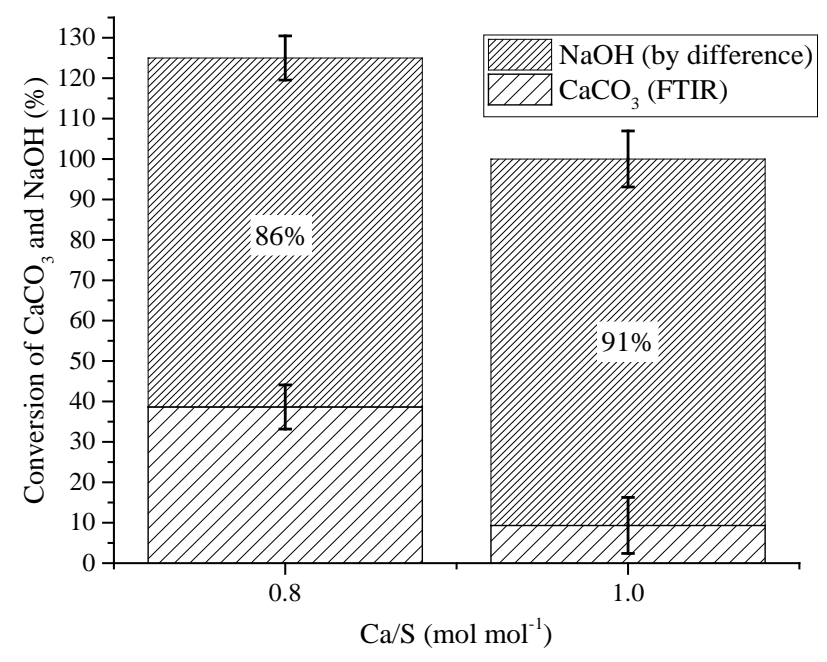

Figure 3. Results from the $\mathrm{NaOH}-\mathrm{H}_{2} \mathrm{SO}_{4}$-lube oil batch reactor experiments, showing the accumulative percentage conversions of $\mathrm{NaOH}$ and $\mathrm{CaCO}_{3}$ at two different $\mathrm{Ca} / \mathrm{S}$. Error bars represent two times the sample standard deviation based on two repetitions.

At $\mathrm{Ca} / \mathrm{S}=1,91 \%$ conversion of the $\mathrm{NaOH}$ was found, whereas only $9 \%$ of the $\mathrm{CaCO}_{3}$ was converted. At $\mathrm{Ca} / \mathrm{S}$ $=0.8,86 \%$ conversion of the $\mathrm{NaOH}$ and $39 \%$ conversion of the $\mathrm{CaCO}_{3}$ was observed. For both $\mathrm{Ca} / \mathrm{S} \mathrm{molar}$ ratios, most of the $\mathrm{H}_{2} \mathrm{SO}_{4}$ reacted with the $\mathrm{NaOH}$, while only a minor fraction reacted with the $\mathrm{CaCO}_{3}$ reverse micelles. From these results, it can be concluded that the $\mathrm{H}_{2} \mathrm{SO}_{4}-\mathrm{CaCO}_{3}$ reaction is significantly slower than the $\mathrm{H}_{2} \mathrm{SO}_{4}-\mathrm{NaOH}$ reaction, and is thus too slow to be diffusion-controlled.

Wu et al. ${ }^{22}$ found that increasing the concentration of nonionic surfactant in a model oil increased the particle size of the reverse micelles (still in the nanometer-range though), consequently increasing the neutralization rate of the $\mathrm{H}_{2} \mathrm{SO}_{4}$ droplet. They attributed this to the enlarged reverse micelles having space to accommodate more water and $\mathrm{H}_{2} \mathrm{SO}_{4}$, upon sticking to the oil-acid interface. However, they also suggested that the addition of 
nonionic surfactants may make the tails of the surfactants more flexible and thus the access of $\mathrm{H}_{2} \mathrm{SO}_{4}$ to the $\mathrm{CaCO}_{3}$-core more feasible. This may facilitate the transport of $\mathrm{H}_{2} \mathrm{SO}_{4}$ into the reverse micelles, thereby increasing the neutralization rate when adding nonionic surfactants. However, it is difficult to directly compare the experiments performed by Wu et al. with the experiments performed in the batch reactor, because larger $\mathrm{NaOH}$ droplets were used in the present work and the effect of $\mathrm{CaCO}_{3}$ reverse micelle size on neutralization rate was not isolated.

In conclusion, the batch reactor experiments support the findings of Hone et al., ${ }^{31}$ that the neutralization reaction between $\mathrm{H}_{2} \mathrm{SO}_{4}$ droplets and $\mathrm{CaCO}_{3}$ reverse micelles cannot be diffusion-controlled. The mixed flow reactor experiments described next, serve to investigate the possible remaining rate-limiting steps.

\subsection{Mixed flow reactor experiments}

The MFR experiments serve both to partly provide information on the rate-limiting steps in the neutralization and partly as data for modeling validation. The data obtained in our previous work ${ }^{38}$ were complemented in the present work with additional experiments, in order to increase the number of repetitions as well as to obtain data at a $\mathrm{Ca} / \mathrm{S}$ molar ratio approaching unity at varying stirrer speeds (to clarify the effect of macromixing). The experimental conditions of the expanded work for each experimental number are supplied in Supporting Information, which also contains data on the effects of residence time and inlet $\mathrm{H}_{2} \mathrm{SO}_{4}$ concentration on the $\mathrm{CaCO}_{3}$ conversion.

\section{Stirrer speed}

The neutralization reaction could conceivably be limited by the rate of macromixing. Even when maximum stirrer speed is applied, perfect mixing might not be achieved in the MFR. Therefore, insufficient contact between $\mathrm{H}_{2} \mathrm{SO}_{4}$ droplets and $\mathrm{CaCO}_{3}$ micelles may arise, resulting in local regions with an excess of $\mathrm{H}_{2} \mathrm{SO}_{4}$ droplets in the lube oil compared to $\mathrm{CaCO}_{3}$, and consequently incomplete reaction of the added $\mathrm{H}_{2} \mathrm{SO}_{4}$. 
Figure 4 shows the effect of stirrer speed $N(1200 \mathrm{rpm}, 600 \mathrm{rpm}$, and $360 \mathrm{rpm})$ on the $\mathrm{CaCO}_{3}$ conversion in the lube oil. The dotted line presents the theoretical conversion of $\mathrm{CaCO}_{3}$ in lube oil and added $\mathrm{H}_{2} \mathrm{SO}_{4}$ when the reaction between $\mathrm{CaCO}_{3}$ and $\mathrm{H}_{2} \mathrm{SO}_{4}$ droplets is complete, i.e. all added $\mathrm{H}_{2} \mathrm{SO}_{4}$ has reacted since Ca/S ratio $\geq 1$. The effect of reducing the stirrer speed by a factor of around three is negligible, both for the Fast Analysis and Complete Conversion Analysis conversions, as well as for both $\mathrm{Ca} / \mathrm{S}$ molar ratios.

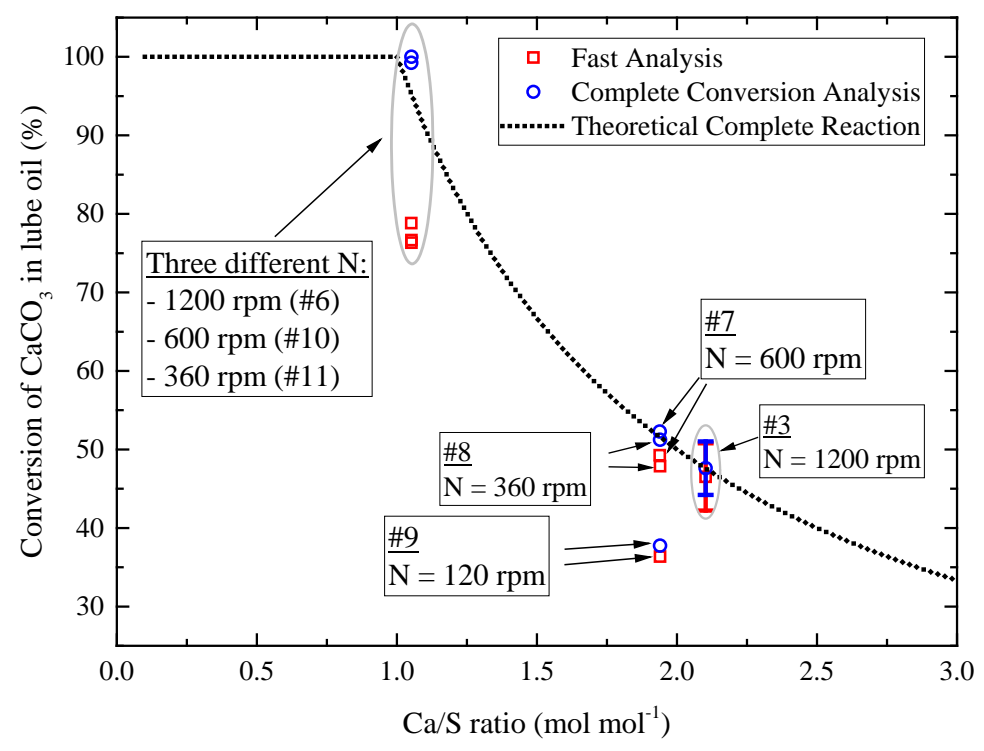

Figure 4. Effect of varying the stirrer speed $(N)$ on the $\mathrm{CaCO}_{3}$ conversion in the lube oil. Error bars represent two times the sample standard deviation. Experimental conditions are: stirrer speed $=120-1200 \mathrm{rpm}$, inlet $\mathrm{H}_{2} \mathrm{SO}_{4}$ concentration $=96.5$ wt.\%, and residence time (for Fast Analysis) $=2.1-2.8$ min (see Table S1 in Supporting Information for more information on each experimental number).

The stirrer speed affects the macromixing in the reactor, as well as the solubilization of $\mathrm{H}_{2} \mathrm{SO}_{4}$ into the lube oil. If the $\mathrm{H}_{2} \mathrm{SO}_{4}-\mathrm{CaCO}_{3}$ reaction had been macromixing-controlled, an effect on the conversion of $\mathrm{CaCO}_{3}$ by decreasing the stirring intensity in the MFR would be expected. This was not the case, and it is concluded that the reaction is not controlled by macromixing when a certain degree of stirring is applied. Further, a reduced conversion of $\mathrm{CaCO}_{3}$ at reduced $\mathrm{Ca} / \mathrm{S}$ values would not be expected for a macromixing-controlled reaction at the same stirring speed. When the stirrer speed is decreased, the solubilization of $\mathrm{H}_{2} \mathrm{SO}_{4}$ into the lube oil may 
also be reduced, leading to an increased size of the $\mathrm{H}_{2} \mathrm{SO}_{4}$ droplets in the lube oil emulsion. Assuming that the reaction is limited by adsorption, this decreases the adsorption rate since the total surface area of the $\mathrm{H}_{2} \mathrm{SO}_{4}$ droplets also decreases. Reducing the stirrer speed by a factor of 10 (120 rpm), yields a conversion of only around $80 \%$ of the added $\mathrm{H}_{2} \mathrm{SO}_{4}$ in the MFR (similar conversions were observed for the fast and complete analysis). The incomplete conversion of $\mathrm{H}_{2} \mathrm{SO}_{4}$ at this low stirrer intensity is attributed to insufficient mixing between $\mathrm{H}_{2} \mathrm{SO}_{4}$ droplets and lube oil, because sedimentation of the heavier $\mathrm{H}_{2} \mathrm{SO}_{4}$ was observed. This implies that most of the $\mathrm{H}_{2} \mathrm{SO}_{4}$ droplets are readily solubilized into the lube oil emulsion upon a minor degree of stirring.

\section{Ca/S molar ratio}

The effect of varying the $\mathrm{Ca} / \mathrm{S}$ molar ratio on the $\mathrm{CaCO}_{3}$ and $\mathrm{H}_{2} \mathrm{SO}_{4}$ conversions is presented in Figs. 5 and 6 . When the Ca/S ratio was larger than 2, complete conversion of $\mathrm{H}_{2} \mathrm{SO}_{4}$ was found in the MFR. ${ }^{38} \mathrm{The}_{2} \mathrm{SO}_{4}$ conversion was observed to decrease when reaching a critically low $\mathrm{Ca} / \mathrm{S}$ ratio of between 1.26 and 2.10. This is attributed to the reaction being micelle adsorption/desorption controlled. At decreasing $\mathrm{Ca} / \mathrm{S}$ ratios, significantly fewer $\mathrm{CaCO}_{3}$ reverse micelles encircle each $\mathrm{H}_{2} \mathrm{SO}_{4}$ droplet. The reduced conversion of $\mathrm{H}_{2} \mathrm{SO}_{4}$ at lower $\mathrm{Ca} / \mathrm{S}$ ratios can therefore be explained by a decrease in adsorption rate of the $\mathrm{CaCO}_{3}$ micelles on the $\mathrm{H}_{2} \mathrm{SO}_{4}$ droplet, ${ }^{46}$ thus reducing the total reaction rate of $\mathrm{CaCO}_{3}$ micelles. It is expected that a high bulk concentration of the adsorbate (in this work $\mathrm{CaCO}_{3}$ reverse micelles) leads to a high coverage of sites on a surface $\left(\mathrm{H}_{2} \mathrm{SO}_{4}\right.$ droplet surface) ${ }^{44}$ thereby increasing the likelihood of the reaction mechanism being controlled by desorption. This situation corresponds to a high $\mathrm{Ca} / \mathrm{S}$, where no apparent limitation is found $(\mathrm{Ca} / \mathrm{S}$ ratio $>2$ in e.g. Figure 5$)$. When fewer micelles are surrounding each droplet (corresponding to a low $\mathrm{Ca} / \mathrm{S}$ value), the driving force from bulk to the surface is also decreased, thereby approaching adsorption-control. 


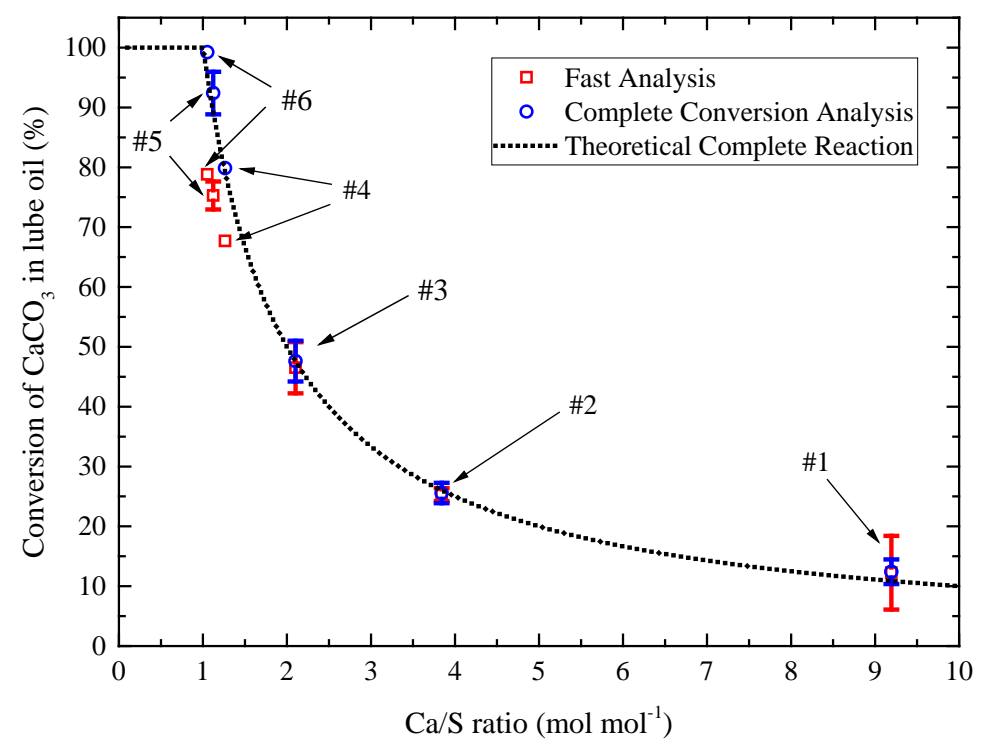

Figure 5. Effect of varying $\mathrm{Ca} / \mathrm{S}$ molar ratio on the $\mathrm{CaCO}_{3}$ conversion in the lube oil. Error bars represent two times the sample standard deviation. Experimental conditions are: stirrer speed $=1200 \mathrm{rpm}$, inlet $\mathrm{H}_{2} \mathrm{SO}_{4}$ concentration $=96.5$ wt.\%, and residence time $($ for Fast Analysis) $=2.1-3.5$ min $($ see Table S1 in Supporting Information for more information on each experimental number).

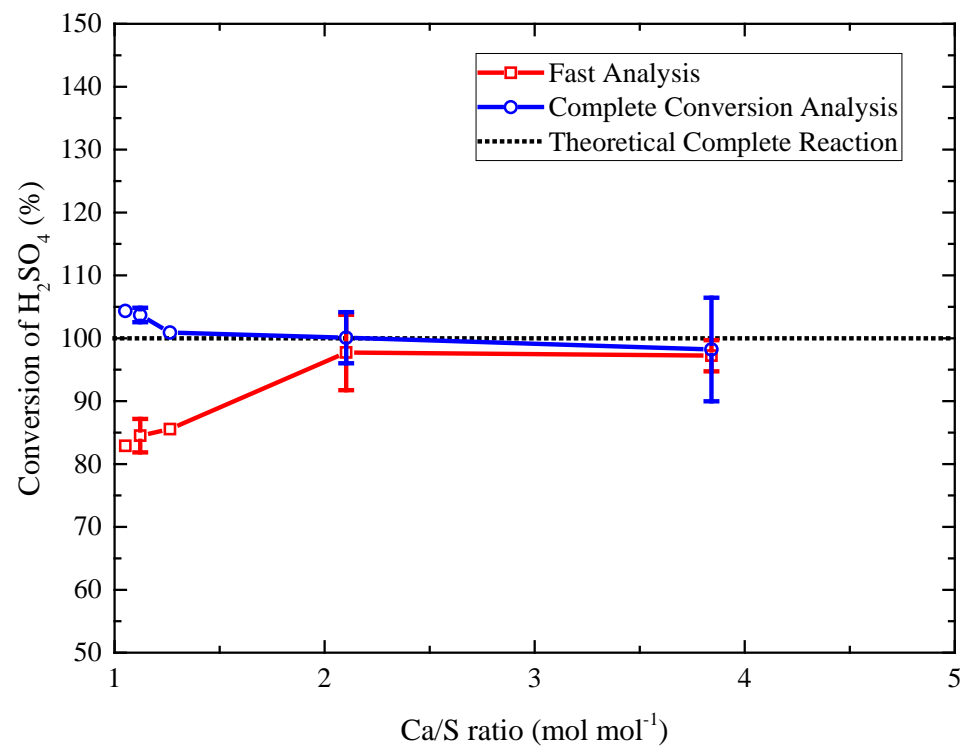

Figure 6. Effect of varying the $\mathrm{Ca} / \mathrm{S}$ molar ratio on the $\mathrm{H}_{2} \mathrm{SO}_{4}$ conversion. Error bars represent two times the sample standard deviation. Experimental conditions as in Figure 5. 
Wu et al. ${ }^{20}$ observed the formation of crystals $\left(\mathrm{CaSO}_{4}\right.$ from the neutralization reaction), which may deposit on the surface of the $\mathrm{H}_{2} \mathrm{SO}_{4}$ droplet, inhibiting further reaction (i.e., desorption-control). However, the occurrence of crystal formation depends on the lube oil formulation; ${ }^{25}$ the reaction products may be solubilized into the lube oil if the lube oil is formulated with the suitable dispersants. Assuming that a stable emulsion is formed when $\mathrm{H}_{2} \mathrm{SO}_{4}$ is introduced into the lube oil (droplet radii in the range 1-10 $\mu \mathrm{m}^{45}$ ), it is expected that inhibition by $\mathrm{CaSO}_{4}$ crystal formation is not a concern. Wu et al. ${ }^{21}$ further suggested that the adsorption of $\mathrm{CaCO}_{3}$ micelles on the acid droplet ( $\mu$ m-sized) interface is the controlling step in the neutralization reaction mechanism. The arguments and experimental results presented in this section support this conclusion.

\section{Mathematical modeling}

\subsection{Reaction rate expressions}

The simulated degree of conversion of the $\mathrm{H}_{2} \mathrm{SO}_{4}$ droplets by the $\mathrm{CaCO}_{3}$ reverse micelles is determined by the reaction rate expression. In section 3 , we conclude that reverse micelle adsorption onto the $\mathrm{H}_{2} \mathrm{SO}_{4}$ droplets is most likely the limiting step in the neutralization mechanism at well-mixed conditions, in line with the literature investigations. ${ }^{21}$ However, early modeling studies ${ }^{39-41}$ indicated that the neutralization reaction may be acid diffusion-controlled. In this study, a reaction rate expression that accounts for both micelle diffusion- and adsorption-resistance will be set up for comparison and the rate-limiting step identified.

\subsubsection{Diffusion-controlled reaction rate expression}

Under diffusion-control, a reaction occurs instantaneously upon collision. The $\mathrm{CaCO}_{3}$ reverse micelles move by Brownian motion, ${ }^{20,22}$ and due to their small size a high collision rate with the $\mathrm{H}_{2} \mathrm{SO}_{4}$ droplets is expected. An expression for the reaction rate was derived following Laidler, ${ }^{44}$ assuming that the $\mathrm{H}_{2} \mathrm{SO}_{4}$ droplets are immobile compared to the much smaller $\mathrm{CaCO}_{3}$ reverse micelles. This assumption is justified since the radius of the 
$\mathrm{H}_{2} \mathrm{SO}_{4}$ droplets is in the $\mu \mathrm{m}$-range, ${ }^{45,47,48}$ whereas the radius of the $\mathrm{CaCO}_{3}$ reverse micelles is in the nmrange. ${ }^{12,20,21,49-52}$ The diffusion-controlled reaction rate constant, $k_{\text {diff }}$, is given as: ${ }^{44}$

$k_{\text {diff }}=4 \pi D_{L} d_{c} N_{A}$

$N_{A}$ is Avogadro's constant and $d_{c}$, the critical distance from a droplet where a $\mathrm{CaCO}_{3}$ reverse micelle immediately reacts under diffusion control, is assumed to be equal to the radius of the $\mathrm{H}_{2} \mathrm{SO}_{4}$ droplet, $R_{S A}$ (at $R=R_{S A}, C_{L}=0$ ). The diffusion coefficient of $\mathrm{CaCO}_{3}$ reverse micelles, $D_{L}$, is given as: ${ }^{44}$

$D_{L}=\frac{k_{B} T}{6 \pi \eta R_{L}}$

Here, $k_{B}$ is the Boltzmann constant, $T$ is the temperature of the lube oil volume, $R_{L}$ is the radius of the $\mathrm{CaCO}_{3}$ reverse micelles, and $\eta$ is the viscosity of the lube oil. The diffusion coefficient of the $\mathrm{CaCO}_{3}$ reverse micelles increases with decreasing lube oil viscosity. The dependence of temperature follows the viscosity temperaturedependency, which is typically a strong function of temperature. ${ }^{47}$

The micelle-diffusion controlled reaction rate is first order with respect to each reactant $\left(\mathrm{H}_{2} \mathrm{SO}_{4}\right.$ droplet and $\mathrm{CaCO}_{3}$ micelle, respectively), and is given by ${ }^{39-41}$ :

$\left(-r_{A, \text { diff }}\right)=k_{\text {diff }} C_{S A} C_{L}$

The concentrations of sulfuric acid $C_{S A}$ and reverse micelles $C_{L}$ are given as:

$C_{S A}=N_{S A} V_{S A} C_{S A, d}$

$C_{L}=N_{L} n_{L}=N_{L} \frac{V_{L} f_{L} \rho_{L}}{M_{L}}$

$N_{S A}$ is the number of $\mathrm{H}_{2} \mathrm{SO}_{4}$ droplets per unit volume of lube oil, $V_{S A}$ is the volume of one droplet, $C_{S A, d}$ is the concentration of $\mathrm{H}_{2} \mathrm{SO}_{4}$ in the droplets, $N_{L}$ is the number of micelles in the lube oil volume, $n_{L}$ is the moles of $\mathrm{CaCO}_{3}$ in one micelle, $V_{L}$ is the volume of one micelle, $f_{L}$ is the volume fraction of $\mathrm{CaCO}_{3}$ in a micelle, $\rho_{L}$ is the density of $\mathrm{CaCO}_{3}$, and $M_{L}$ is the molar weight of $\mathrm{CaCO}_{3}$. The diffusion-controlled reaction rate constant only 
contains physical parameters and can thereby be calculated directly from the expressions given in Eqs. (3) and (4).

\subsubsection{Adsorption-controlled reaction rate expression}

Molar rate balances of $\mathrm{H}_{2} \mathrm{SO}_{4}$ droplets and $\mathrm{CaCO}_{3}$ reverse micelles are formulated to extract an adsorptioncontrolled reaction rate constant expression. The molar $\mathrm{H}_{2} \mathrm{SO}_{4}$ consumption rate of one droplet is:

$-\frac{d n_{S A}}{d t}=-\frac{d\left(V_{S A} C_{S A, d}\right)}{d t}=4 \pi R_{S A}^{2} C_{S A, d}\left(-\frac{d R_{S A}}{d t}\right)$

The molar adsorption rate of $\mathrm{CaCO}_{3}$ reverse micelles to the surface of a $\mathrm{H}_{2} \mathrm{SO}_{4}$ droplet is expressed as: ${ }^{.4}$

$-\frac{d n_{L}}{d t}=\mathrm{A}_{S A} k_{a d s} C_{L}(1-\theta)$

Here, $k_{a d s}$ is the adsorption-controlled reaction rate constant with the unit $\mathrm{m} \mathrm{s}^{-1}$, $\theta$ is the fraction of $\mathrm{H}_{2} \mathrm{SO}_{4}$ droplet surface that is covered by micelles, and $A_{S A}$ is the surface area of the $\mathrm{H}_{2} \mathrm{SO}_{4}$ droplet. For an adsorptioncontrolled process, it is assumed that $\theta=0 .{ }^{24}$ This means that immediately after a successful collision (adsorption) of a micelle onto the droplet surface, reaction occurs, followed by immediate desorption of the product back into the bulk. According to Eq. (9), the reaction rate depends on the concentration of $\mathrm{CaCO}_{3}$ reverse micelles (or $\mathrm{BN}$ ), which is in agreement with previous investigations. ${ }^{21,35}$ The molar consumption rate of $\mathrm{H}_{2} \mathrm{SO}_{4}$, Eq. (8), can be set equal to the molar adsorption rate of $\mathrm{CaCO}_{3}$ reverse micelles onto the $\mathrm{H}_{2} \mathrm{SO}_{4}$ droplets, Eq. (9). Solving for $k_{a d s}$ gives:

$k_{a d s}=\left(-\frac{d R_{S A}}{d t}\right) \frac{C_{S A, d}}{C_{L}}$

The overall adsorption-controlled reaction rate is derived by multiplying Eq. (9) with $N_{S A}$ and introducing Eq.

(6):

$\left(-r_{A, a d s}\right)=\frac{A_{S A}}{V_{S A}} \frac{1}{C_{S A, d}} k_{a d s} C_{S A} C_{L}$ 
Note, that the micelle-diffusion and micelle-adsorption rate equations (Eqs. (5) and (11)) are identical, and only the rate constants are different.

\subsubsection{Estimation of adsorption controlled reaction rate constant}

Values for the $\mathrm{H}_{2} \mathrm{SO}_{4}$ droplet shrinking rate, $\left(-d R_{S A} / d t\right)$, were determined from the video-microscopy experiments by $\mathrm{Fu}$ et al. ${ }^{24}$ in the temperature range 298 to $443 \mathrm{~K}$ for $\mathrm{H}_{2} \mathrm{SO}_{4}$ droplets in fully-formulated lube oil. A strong dependence of temperature was found; by increasing the temperature from 298 to $443 \mathrm{~K}$, the shrinking rate increased by a factor of more than 1000. A linear relation between $\ln \left(-d R_{S A} / d t\right)$ and $1 / T$ was also found, and a modified Arrhenius type plot was constructed. The following relation between shrinking rate and temperature can be established as:

$-\frac{d R_{S A}}{d t}=11.3 \frac{\mathrm{m}}{\mathrm{s}} \exp \left(-\frac{52.8 \frac{\mathrm{kJ}}{\mathrm{mol}}}{R T}\right)$

Here $R$ is the ideal gas constant. The derived activation energy, $E_{a}$, of $52.8 \mathrm{~kJ} \mathrm{~mol}^{-1}$, is in excellent agreement with the value of $54 \pm 2 \mathrm{~kJ} \mathrm{~mol}^{-1}$ found by Hone et al. ${ }^{31}$ Duan et al. ${ }^{53}$ reported activation energies in the range 27.0-30.7 $\mathrm{kJ} \mathrm{mol}^{-1}$ for neutralization of acetic acid droplets in passenger-car lube oil, but this reaction involved a different mechanism compared to that of an $\mathrm{H}_{2} \mathrm{SO}_{4}$ droplet in marine lube oil.

$\mathrm{Fu}$ et al. used a lube oil with a base number of 70 and $50 \mathrm{vol} \% \mathrm{H}_{2} \mathrm{SO}_{4}$ droplets, corresponding to a concentration of $\mathrm{CaCO}_{3}$ of $C_{L}=586.5 \mathrm{~mol} \mathrm{~m}^{-3}$ and an acid concentration of $C_{S A}=9.4 \cdot 10^{3} \mathrm{~mol} \mathrm{~m}^{-3}$. Substituting Eq. (12) into Eq. (10) and inserting the concentrations, the following expression for $k_{a d s}$ can be calculated:

$k_{a d s}=180.6 \frac{\mathrm{m}}{\mathrm{s}} \exp \left(-\frac{52.8 \frac{\mathrm{kJ}}{\mathrm{mol}}}{R T}\right)$ 
Equation (11), with $k_{a d s}$ from Eq. (13), provides a quantitative expression for the neutralization reaction under adsorption control.

\subsubsection{Resulting reaction rate constant}

An expression for a combined reaction rate constant, $k_{r e s}$, can now be derived taking into account contributions from both the diffusion-controlled and adsorption-controlled reaction rate constant:

$$
k_{\text {res }}=\frac{1}{\frac{1}{k_{\text {diff }}}+\frac{1}{\frac{A_{S A}}{V_{S A}} \frac{1}{C_{S A, d}} k_{a d s}}}=\frac{1}{\frac{1}{k_{\text {diff }}}+\frac{R_{S A} C_{S A, d}}{3 k_{a d s}}}=\frac{1}{\frac{1}{k_{\text {diff }}}+\frac{1}{k_{\text {ads }}^{\prime}}}
$$

Here $k_{a d s}^{\prime}$ is given as:

$$
k_{a d s}^{\prime}=\frac{3 k_{a d s}}{R_{S A} C_{S A, d}}
$$

The resulting reaction rate is then calculated as:

$$
\left(-r_{A, r e s}\right)=k_{\text {res }} C_{S A} C_{L}
$$

\subsection{Reactor System}

A schematic illustration of the $\mathrm{H}_{2} \mathrm{SO}_{4}$ droplets-lube oil system in the mixed flow reactor setup is shown in Figure 7. The reactor has inlet flows for lube oil and $\mathrm{H}_{2} \mathrm{SO}_{4}$ droplets. The outlet flow serves to maintain a specific oil volume, $V_{\text {oil }}$. The lube oil volume is well-mixed, and the $\mathrm{H}_{2} \mathrm{SO}_{4}$ droplets are therefore mixed immediately into the oil, forming a stable water-in-oil emulsion. The well-mixed conditions in the MFR resemble those of an actual engine cylinder, where the high velocity of the piston conceivably leads to a wellmixed region in front of the piston. The $\mathrm{H}_{2} \mathrm{SO}_{4}$ droplets with a uniform droplet radius of $R_{S A}$ and concentration $C_{S A, d}$ are fed to the mixed flow reactor with a flow rate $F_{S A}$. The lube oil dosage is continuous, with a flow rate 
$v_{o i l, f}$, containing $\mathrm{CaCO}_{3}$ reverse micelles in the concentration $N_{L, f}$. The lube oil outlet flow, $v_{o}$, contains unreacted $\mathrm{CaCO}_{3}$ reverse micelles in the concentration, $N_{L}$, and the $\mathrm{H}_{2} \mathrm{SO}_{4}$ droplets concentration is $N_{S A}$ (if any).

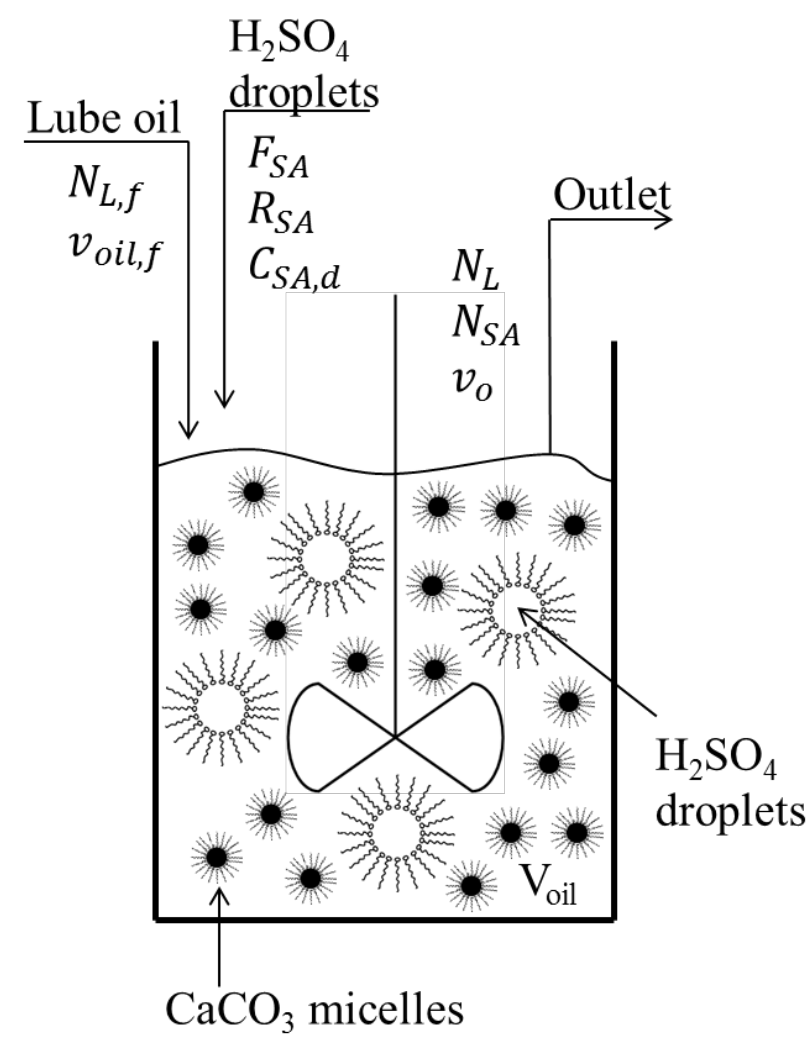

Figure 7. Schematic illustration of the neutralization of $\mathrm{H}_{2} \mathrm{SO}_{4}$ droplets in a lube oil by $\mathrm{CaCO}_{3}$ reverse micelles under mixed flow reactor conditions. Lube oil volume and inlet and outlet conditions are indicated in the figure.

\subsection{Mathematical Model}

The present model describes the neutralization of $\mathrm{H}_{2} \mathrm{SO}_{4}$ droplets in a stirred lube oil volume containing $\mathrm{CaCO}_{3}$ reverse micelles. The assumptions underlying the model are:

- The lube oil volume is well-mixed (no radial or axial concentration or temperature gradients) and in steady state with continuous, uniform feeding of lube oil and $\mathrm{H}_{2} \mathrm{SO}_{4}$ droplets. 
- The outlet flow of lube oil, $v_{o}$, is equal to the sum of the inlet flows of lube oil, $v_{o i l, f}$, and the droplets, $v_{S A, f}$. The reduction in outlet lube oil flow due to $\mathrm{CO}_{2}(\mathrm{~g})$ formation is not taken into account.

- The $\mathrm{H}_{2} \mathrm{SO}_{4}$ droplets are readily solubilized into the lube oil by excess surfactants, as a water-in-oil emulsion.

- $\quad$ The only reaction considered in the lube oil is: $\mathrm{CaCO}_{3}(\mathrm{~s})+\mathrm{H}_{2} \mathrm{SO}_{4}(\mathrm{aq}) \rightarrow \mathrm{CaSO}_{4}(\mathrm{~s})+\mathrm{CO}_{2}(\mathrm{~g})+\mathrm{H}_{2} \mathrm{O}$ (l) with a reaction rate $\left(-r_{A}\right)$.

- The $\mathrm{CaSO}_{4}$ formation does not limit the neutralization reaction.

- The $\mathrm{CaCO}_{3}$ micelles and $\mathrm{H}_{2} \mathrm{SO}_{4}$ droplets are spherical and uniform in size.

- Shrinking over time of $\mathrm{CaCO}_{3}$ micelles and $\mathrm{H}_{2} \mathrm{SO}_{4}$ droplets is not taken into account; only consumption of entire droplets/micelles is considered.

\subsection{1 $\mathrm{H}_{2} \mathrm{SO}_{4}$ number balance over mixed flow reactor}

A number balance for $\mathrm{H}_{2} \mathrm{SO}_{4}$ droplets is given as:

$$
\underbrace{F_{S A}}_{\text {In }}-\underbrace{\frac{\left(-r_{A}\right) V_{\text {oil }} M_{S A}}{\rho_{S A}\left(V_{S A}-V_{S A, o}\right) \frac{C_{S A, d} M_{S A}}{\rho_{S A}}}}_{\text {Produced }}=\underbrace{N_{S A} v_{0}}_{\text {Out }}
$$

Here $F_{S A}$ is the inlet $\mathrm{H}_{2} \mathrm{SO}_{4}$ droplet number flow, $V_{\text {oil }}$ is the volume of lube oil in the reactor, $M_{S A}$ is the molar weight of $\mathrm{H}_{2} \mathrm{SO}_{4}, \rho_{S A}$ is the density of $\mathrm{H}_{2} \mathrm{SO}_{4}$, and $v_{o}$ is the volumetric outflow. The term $C_{S A, d} M_{S A} / \rho_{S A}$ is the volume fraction of $\mathrm{H}_{2} \mathrm{SO}_{4}$ in the droplets. The term $\left(V_{S A}-V_{S A, o}\right)$ accounts for the volume change of a $\mathrm{H}_{2} \mathrm{SO}_{4}$ droplet. $V_{S A}$ is the initial volume of a $\mathrm{H}_{2} \mathrm{SO}_{4}$ droplet and $V_{S A, o}$ is the volume of a $\mathrm{H}_{2} \mathrm{SO}_{4}$ droplet in the outlet. The latter is equal to 0 corresponding to a situation where a $\mathrm{H}_{2} \mathrm{SO}_{4}$ droplet is completely consumed. The volumetric outflow rate of lube oil emulsion, $v_{o}$, is equal to the sum of the volumetric inlet flow rates of lube oil, $v_{o i l, f}$, and $\mathrm{H}_{2} \mathrm{SO}_{4}$ droplets, $v_{S A, f}$ :

$v_{o}=v_{o i l, f}+v_{S A, f}=v_{o i l, f}+F_{S A} V_{S A}$ 


\subsubsection{Reverse micelle number balance over mixed flow reactor}

A number balance for the reverse micelles in the lube oil volume reads:

$\underbrace{N_{L, f} v_{\text {oil,f }}}_{\text {In }}-\underbrace{\frac{\left(-r_{A}\right) V_{\text {oil }} M_{L}}{\rho_{L}\left(V_{L} f_{L}-V_{L, o} f_{L, o}\right)}}_{\text {Produced }}=\underbrace{N_{L} v_{o}}_{\text {Out }}$

Again, the term $V_{L, o} f_{L, o}$ is equal to 0 since only the complete consumption of $\mathrm{CaCO}_{3}$ reverse micelles is considered. $N_{L, f}$ is the number of $\mathrm{CaCO}_{3}$ reverse micelles per volume of lube oil in the inlet feed, given as:

$N_{L, f}=\frac{f_{L, o i l, w} \rho_{o i l}}{\rho_{L} V_{L} f_{L}}$

$f_{L, o i l, w}$ is the weight fraction of $\mathrm{CaCO}_{3}$ in the fresh lube oil, and $\rho_{\text {oil }}$ is the density of the lube oil.

\subsubsection{Ca/S molar ratio}

It is of interest to investigate how the $\mathrm{H}_{2} \mathrm{SO}_{4}$ droplet flow into the lube oil volume affects the conversion of the $\mathrm{H}_{2} \mathrm{SO}_{4}$ droplets and $\mathrm{CaCO}_{3}$ reverse micelles in the lube oil film. This is done by introducing the molar ratio of $\mathrm{CaCO}_{3}$ to $\mathrm{H}_{2} \mathrm{SO}_{4}$ in the inlet feed, $\mathrm{Ca} / \mathrm{S}$, defined from the molar balance:

$C a / S=\frac{v_{o i l, f} \rho_{o i l} f_{L, o i l, w}}{M_{L} F_{S A} V_{S A} C_{S A, d}}$

Solving for $F_{S A}$ gives:

$F_{S A}=\frac{v_{o i l, f} \rho_{o i l} f_{L, o i l, w}}{M_{L} V_{S A} C_{S A, d} C a / S}$

By substituting Eq. (22) into Eq. (17), the parameter $\mathrm{Ca} / \mathrm{S}$ is now the independent variable. When $\mathrm{Ca} / \mathrm{S}$ is equal to 1 , then $\mathrm{H}_{2} \mathrm{SO}_{4}$ and $\mathrm{CaCO}_{3}$ are present in stoichiometric amounts. 


\subsubsection{Estimation of model parameters}

Chemical and physical properties for the $\mathrm{H}_{2} \mathrm{SO}_{4}$ droplets and $\mathrm{CaCO}_{3}$ reverse micelles are shown in Table 1 , together with typical operating conditions.

Table 1. Chemical and physical parameters for the $\mathrm{H}_{2} \mathrm{SO}_{4}$ droplets, $\mathrm{CaCO}_{3}$ reverse micelles, and lube oil.

\begin{tabular}{|l|l|l|}
\hline Parameter & Parameter Value & Reference \\
\hline$R_{L}$ & $5 \cdot 10^{-9} \mathrm{~m}$ & $12,20,21,49-52$ \\
\hline$f_{L}$ & $0.3 \mathrm{~m}^{3} \mathrm{~m}^{-3}$ & $12,20,21,49-52$ \\
\hline$f_{L, \text { oil }, w}$ & $0.088 \mathrm{~kg} \mathrm{~kg}^{-1}(98.55 \mathrm{BN})$ & Measured \\
\hline$\rho_{\text {oil }}$ & $940 \mathrm{~kg} \mathrm{~m}^{-3}$ & Measured \\
\hline$\rho_{L}$ & $2710 \mathrm{~kg} \mathrm{~m}^{-3}$ & 54 \\
\hline$\rho_{S A}$ & $1840 \mathrm{~kg} \mathrm{~m}^{-3}(\mathrm{pure})$ & 55 \\
\hline$M_{S A}$ & $98.1 \cdot 10^{-3} \mathrm{~kg} \mathrm{~mol}^{-1}$ & Calculated \\
\hline$M_{L}$ & $100.1 \cdot 10^{-3} \mathrm{~kg} \mathrm{~mol}^{-1}$ & Calculated \\
\hline$C_{S A, d}$ & $18 \cdot 10^{3} \mathrm{~mol} \mathrm{~m}^{-3}(96.5 \mathrm{wt} . \%)$ & Calculated \\
\hline$\tau$ & $126 \mathrm{~s}$ & Measured \\
\hline$V_{\text {oil }}$ & $1.2 \cdot 10^{-4} \mathrm{~m}^{3}$ & Measured \\
\hline$T$ & $327 \mathrm{~K}$ & Measured \\
\hline$\eta(327 \mathrm{~K})$ & $6.2 \cdot 10^{-2} \mathrm{~kg} \mathrm{~m}^{-1} \mathrm{~s}^{-1}$ & Calculated \\
\hline
\end{tabular}

Tobias and Klein ${ }^{20}$ reported that a typical reverse micelle is roughly spherical, with an average diameter of the $\mathrm{CaCO}_{3}$ core of $2.3 \mathrm{~nm}$ and a surfactant layer thickness of $0.9 \mathrm{~nm}$. This gives a total diameter of the reverse micelle of $4.1 \mathrm{~nm}$. Hudson et al. ${ }^{49}$ reported core diameters in the range $1-10 \mathrm{~nm}$, and a surfactant layer thickness in the range 1-5 nm, yielding total diameters in the range 3-20 nm. Lewis ${ }^{21}$ reported an overall diameter in the range 8-18 nm, with core diameters between 4 and $14 \mathrm{~nm}$. Based on these results, which are generally in accordance with other reported studies, ${ }^{12,50-52}$ an average reverse micelle diameter of $10 \mathrm{~nm}$ is chosen and a volume fraction of $\mathrm{CaCO}_{3}$ in a reverse micelle, $f_{L}$, is estimated to be 0.3 . The radius of the $\mathrm{H}_{2} \mathrm{SO}_{4}$ droplets will be discussed in Section 5.

The average base number (BN) of the lube oil used in the MFR experiments ${ }^{38}$ was 98.55 , corresponding to a weight fraction of $\mathrm{CaCO}_{3}$ in the lube oil of $0.088 \mathrm{~kg} \mathrm{~kg}^{-1}$. The density of $\mathrm{CaCO}_{3}$ was taken from $\mathrm{CRC}^{54}$ the 
density of $\mathrm{H}_{2} \mathrm{SO}_{4}$ from Perry’s ${ }^{55}$ (96.5 wt.\% $\mathrm{H}_{2} \mathrm{SO}_{4}$ solution corresponds to a density of approximately $1840 \mathrm{~kg}$ $\mathrm{m}^{-3}$ ), and the density of the lube oil was measured using a scale and measuring glass.

The lube oil temperature in the MFR experiments was around $327 \mathrm{~K}$. The lube oil viscosity was drawn from Sautermeister and Priest, ${ }^{47}$ who measured the dynamic viscosity for a base oil at different temperatures. For the reference conditions, an average lube oil residence time in the reactor is taken as 126 seconds based on the volumetric feed rate of lube oil, $v_{o i l, f}$, and the average volume of lube oil, $V_{\text {oil }}$, used in the MFR experiments. The two output variables, $N_{L}$ and $N_{S A}$, can be expressed as the conversion of $\mathrm{CaCO}_{3}, X_{L}$, and $\mathrm{H}_{2} \mathrm{SO}_{4}, X_{S A}$, respectively:

$$
\begin{aligned}
& X_{\mathrm{L}}=1-\frac{N_{L} v_{o}}{N_{L, f} v_{o i l, f}} \\
& X_{\mathrm{SA}}=1-\frac{N_{S A} v_{o}}{F_{S A}}
\end{aligned}
$$

In summary, the model consists of two coupled algebraic equations, Eq. (17) and Eq. (19), which are solved for $N_{L}$ and $N_{S A}$ by use of Matlab, with the parameter $\mathrm{Ca} / \mathrm{S}$ as the independent variable. The model parameters presented in this section have been used for the calculations that follow in the next section, unless otherwise stated.

\section{Validation of mathematical model against MFR results}

To validate the model and investigate the rate-controlling step of the neutralization reaction between $\mathrm{H}_{2} \mathrm{SO}_{4}$ droplets and $\mathrm{CaCO}_{3}$ reverse micelles, model simulations are compared to experimental data from the MFR, by applying diffusion- and adsorption-controlled reaction rate expressions.

The first step is to investigate the relative resistance with respect to diffusion and adsorption based on Eq. (14). The resulting reaction rate constant, $k_{r e s}$, is calculated by use of the parameters given in Table 1 . The only parameter not available and required for the calculation is the radius of the $\mathrm{H}_{2} \mathrm{SO}_{4}$ droplets, $R_{S A}$. Applying typical particle radii for a stable emulsion of $1-10 \mu \mathrm{m}^{45}$ reveals that $k_{r e s}=k_{a d s}^{\prime}$, and this is independent of 
temperature for the given radius range. Decreasing the radius of the droplets decreases $k_{\text {diff }}$ (Eq. (3)) and increases $k_{a d s}^{\prime}$ (Eq. (14)). However, to observe a noticeable effect on $k_{r e s}$, the radius of the droplets has to be decreased to $0.04 \mathrm{~nm}$ at $298 \mathrm{~K}$ and $0.2 \mathrm{~nm}$ at $573 \mathrm{~K}$ (to obtain $k_{r e s}=0.99 k_{a d s}^{\prime}$ ), which are orders of magnitude smaller than typical acid droplet sizes of $1-10 \mu \mathrm{m} .{ }^{45}$ This shows that the neutralization reaction is adsorptioncontrolled, in agreement with earlier suggestions from single-droplet experiments. ${ }^{21}$

The only unknown model parameter, $R_{S A}$, was fitted to match the experimental data of $\mathrm{CaCO}_{3}$ conversion from the MFR experiments (Figure 5), by use of a "least squares" approach. For the conditions given in Table 1, a value of $R_{S A}$ equal to $0.5 \mu \mathrm{m}$ was calculated by using the adsorption-controlled reaction rate expression given in Eq. (11). Goodwin ${ }^{45}$ states that most common emulsions have a particle radius in the range of 1-10 $\mu \mathrm{m}$. Typical acid/water droplet radii from used engine lube oils are found to be in the range $2.5-15 \mu \mathrm{m} .{ }^{48}$ This is for a stable emulsion after drainage of the lube oil. Sautermeister and Priest ${ }^{47}$ measured $\mathrm{H}_{2} \mathrm{SO}_{4}$ droplet sizes in a stable base oil emulsion, measuring radii in the range 0.25-1.6 $\mu \mathrm{m}$ depending on the $\mathrm{H}_{2} \mathrm{SO}_{4}$ droplet concentration. Consequently, it is expected that these droplet sizes were instantly formed in the MFR experiments, where large excess of dispersant and detergent molecules are present in the used lube oil. Based on these numbers from the literature, it is concluded that the radius of $0.5 \mu \mathrm{m}$ fitted from the modeling is indeed a realistic value. Modeling predictions for $R_{S A}=0.5 \mu \mathrm{m}$ are compared with the MFR data (Figs. 5 and 6) in Figure 8, along with simulations increasing $R_{S A}$ by factors of 5 and 10, respectively. Modeling predictions with $R_{S A}=0.5 \mu \mathrm{m}$ are further in good agreement with experimental data while larger droplet sizes lead to an underprediction of the degree of reaction. The predicted conversion of $\mathrm{CaCO}_{3}$ and $\mathrm{H}_{2} \mathrm{SO}_{4}$ decreases significantly when increasing the droplet radius. At $\mathrm{Ca} / \mathrm{S}=1$, the conversion of $\mathrm{H}_{2} \mathrm{SO}_{4}$ and $\mathrm{CaCO}_{3}$ is equal to each other. Here, the conversions decrease by $24 \%$ and $37 \%$ when increasing the radius to $2.5 \mu \mathrm{m}$ and $5.0 \mu \mathrm{m}$ respectively, relative to the reference conversion (for $R_{S A}=0.5 \mu \mathrm{m}$ ). This indicates that larger $\mathrm{H}_{2} \mathrm{SO}_{4}$ droplets present in the lube oil film may increase the risk of corrosive wear significantly, ${ }^{25}$ due to the surface to volume ratio of the droplets decreasing when the radius increases, i.e. fewer but bigger droplets. 
Simulations showing the effect of varying the $\mathrm{Ca} / \mathrm{S}$ molar ratio on the conversion of $\mathrm{H}_{2} \mathrm{SO}_{4}$ droplets and $\mathrm{CaCO}_{3}$ reverse micelles by use of the diffusion-controlled reaction rate expression are also depicted in Figure 8 for $R_{S A}$ $=0.5 \mu \mathrm{m}$. Complete conversion of the limiting reactant is predicted to occur independently of $\mathrm{Ca} / \mathrm{S}$. At a Ca/S ratio larger than $1, \mathrm{CaCO}_{3}$ is in molar excess, which is shown by a decrease in $\mathrm{CaCO}_{3}$ conversion, but the conversion of $\mathrm{H}_{2} \mathrm{SO}_{4}$ droplets is 1 , i.e. undergone complete conversion. At a Ca/S lower than $1, \mathrm{H}_{2} \mathrm{SO}_{4}$ is in molar excess compared to $\mathrm{CaCO}_{3}$, and therefore some unreacted $\mathrm{H}_{2} \mathrm{SO}_{4}$ is still present in the lube oil outlet, i.e. complete conversion of $\mathrm{CaCO}_{3}$ is observed. Consequently, by using a micelle diffusion-controlled reaction rate, no limitation is found for the neutralization reaction. The poor agreement at lower $\mathrm{Ca} / \mathrm{S}$ ratios confirms that the neutralization reaction is not diffusion-controlled, even with the present value of the diffusion-controlled reaction rate constant, $2.9 \cdot 10^{6} \mathrm{~m}^{3} \mathrm{~mol}^{-1} \mathrm{~s}^{-1}$, which is a significantly smaller value than the value used by Schramm et al. ${ }^{39}$ and van Helden. ${ }^{40}$
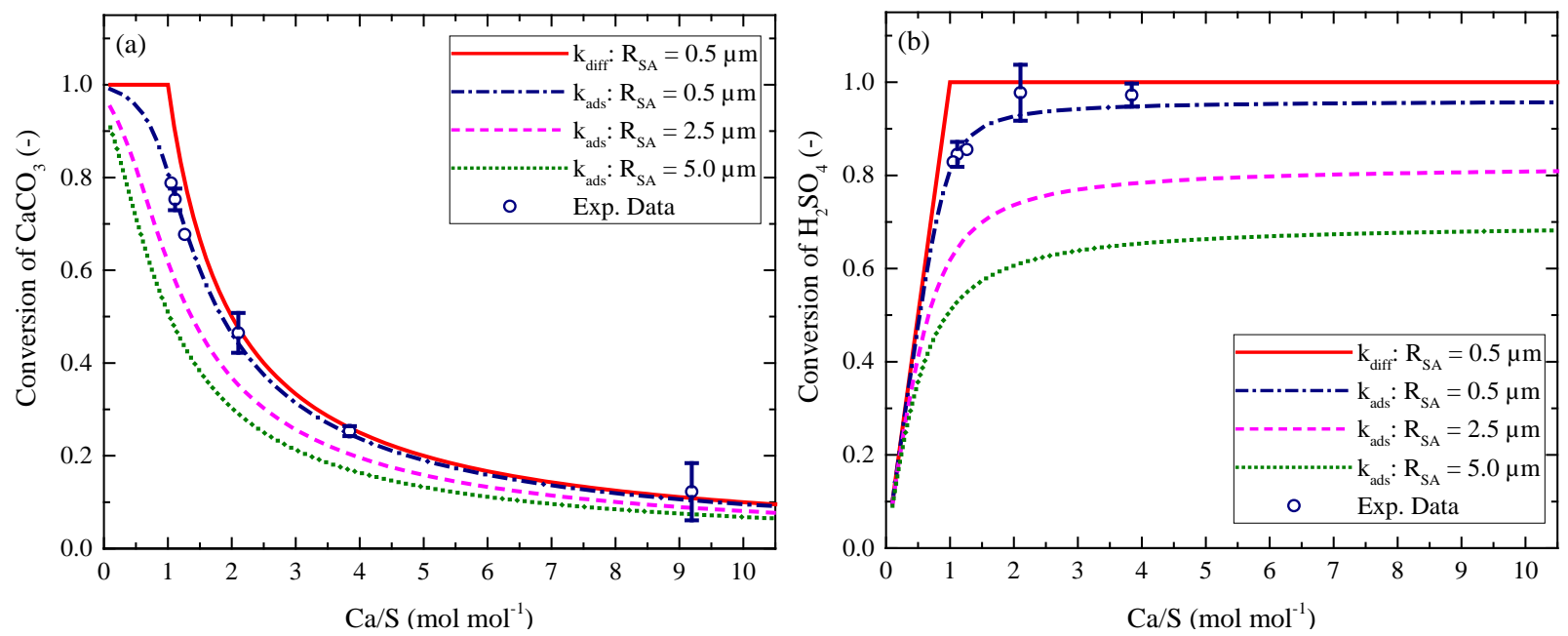

Figure 8. Model simulations showing conversion of (a) $\mathrm{CaCO}_{3}$ reverse micelles and (b) $\mathrm{H}_{2} \mathrm{SO}_{4}$ droplets as a function of $\mathrm{Ca} / \mathrm{S}$ by using a micelle diffusion-controlled reaction rate constant and an adsorption-controlled reaction rate constant at three values of $\mathrm{H}_{2} \mathrm{SO}_{4}$ radius, $R_{S A}$. Circles represent MFR experimental data from Figs. 5 and 6. Model parameters are presented in Table 1.

\subsection{Evaluation of model assumptions}


The adsorption-controlled reaction rate constant expression used in the model simulations, Eq. (13), is based on the video-microscopy single droplet experiments performed by Fu et al., ${ }^{24}$ who reported a shrinking rate. The present model considers only consumption of entire droplets. A model describing reaction of partly-consumed $\mathrm{H}_{2} \mathrm{SO}_{4}$ droplets in the lube oil emulsion would have to take into account a size distribution. However, since the droplets are very small in size ( $1 \mu \mathrm{m}$ in radius), and the size distribution mimics a normal distribution with a low standard deviation, ${ }^{47}$ one would argue that it is fair to assume that whole droplets are immediately consumed upon adsorption.

Another difference is the size of the droplets. Fu et al. used initial droplet sizes in the range of 43.6-76.5 $\mu \mathrm{m}$, reporting that a constant shrinking rate was found up until a certain radius was reached. After this point, the shrinking rate increases. This 'change point' was found to occur at around $28 \mu \mathrm{m}$ at $403 \mathrm{~K}$. Since even smaller $\mathrm{H}_{2} \mathrm{SO}_{4}$ droplets are found in the MFR experiments, the derived reaction rate constant in Eq. (13) may underestimate the actual adsorption rate. Further, Wu et al. ${ }^{21}$ reported significant different shrinking rates for different lube oil formulations having the same BN value. It is not known whether the lube oil used in the study by Fu et al. matches the lube oil used in the MFR experiments.

\section{Application of the MFR model to conditions in a large two-stroke marine diesel engine}

The mixed flow reactor model was developed to interpret the laboratory MFR experiments, while allowing for a validation of the reaction rate expression for the neutralization reaction, which can be used in more complex models. A full simulation of the neutralization reaction at the cylinder liner in a large, two-stroke marine diesel engine would require a computational fluid dynamics approach. However, as discussed in the following, the mixed flow reactor model offers a useful approximation to conditions in the lube oil film and can be used to assess the importance of different process parameters.

In a large two-stroke marine diesel engine, the lube oil- $\mathrm{H}_{2} \mathrm{SO}_{4}$ interactions depend on the piston movement, see Figure 9. Dosing of the lube oil into the piston ring pack occurs during the piston’s upward stroke, Figure 9(a). 
When the piston is at the top dead center (TDC) and moves downwards (expansion stroke, Figure 9(b)), $\mathrm{H}_{2} \mathrm{SO}_{4}$ condensates as droplets (either dilute or pure) onto the distributed lube oil film on the cylinder liner surface. It is believed that condensed $\mathrm{H}_{2} \mathrm{SO}_{4}$ forms a thin film on top of the layer of lube oil film. ${ }^{7,39}$ The condensation of $\mathrm{H}_{2} \mathrm{SO}_{4}$ occurs in the gas phase just before reaching the lube oil film, where the temperature is lower than in the bulk gas phase. ${ }^{6,47,48,56}$ Since no mixing is occurring, transport of $\mathrm{CaCO}_{3}$ micelles to the $\mathrm{H}_{2} \mathrm{SO}_{4}$ happens by diffusion. However, when the piston moves towards TDC (compression stroke, Figure 9(c)), the piston rings act to spread and remove excess lube oil from the cylinder liner. The high velocity of the piston may lead to effective mixing of the condensed $\mathrm{H}_{2} \mathrm{SO}_{4}$ and lube oil at the moving front, in front of the piston ring, thereby emulsifying the $\mathrm{H}_{2} \mathrm{SO}_{4}$ droplets into the lube oil (Figure 9(d)). After the piston has passed a specific point the local lube oil film may be left stagnant, allowing the $\mathrm{H}_{2} \mathrm{SO}_{4}$ to react with the cast iron liner until the next time the piston passes by, when it once again mixes the lube oil film emulsion. The cycle is repeated roughly every $0.5 \mathrm{~s}$, which is the time for one stroke. However, fresh lube oil is not injected in every cycle, instead typically at every third to eighth engine revolution. The cast iron wall temperature would be in the range 373-533 K and highest in the upper part of the cylinder, while the lube oil film is expected to attain the same temperature because of the high heat capacity and thermal conductivity of the cast iron., ${ }^{3,7}$ 
(a)

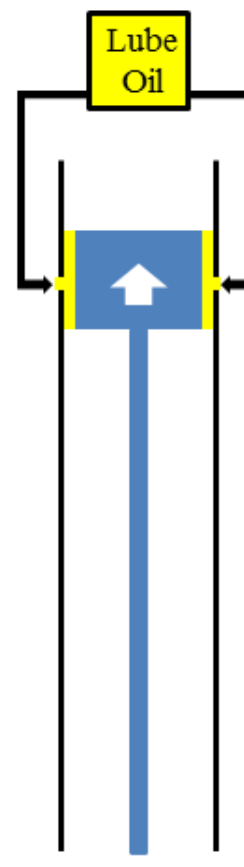

(b)

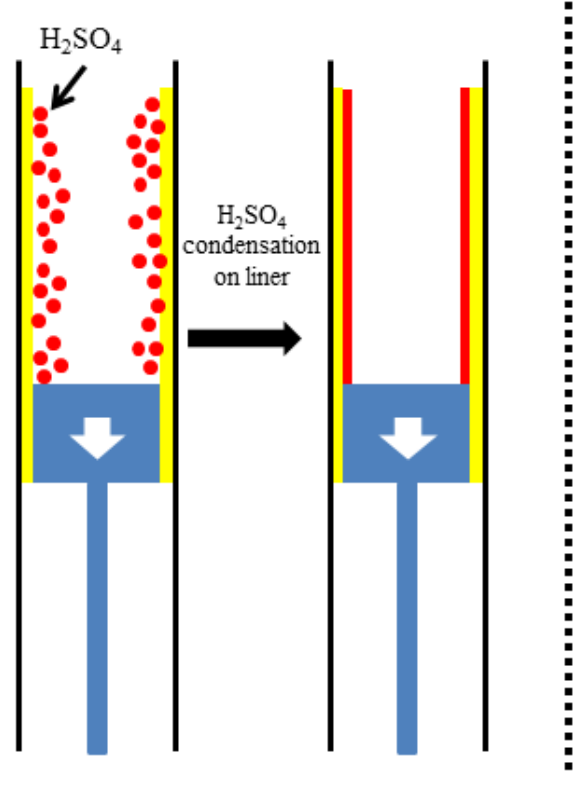

(c)

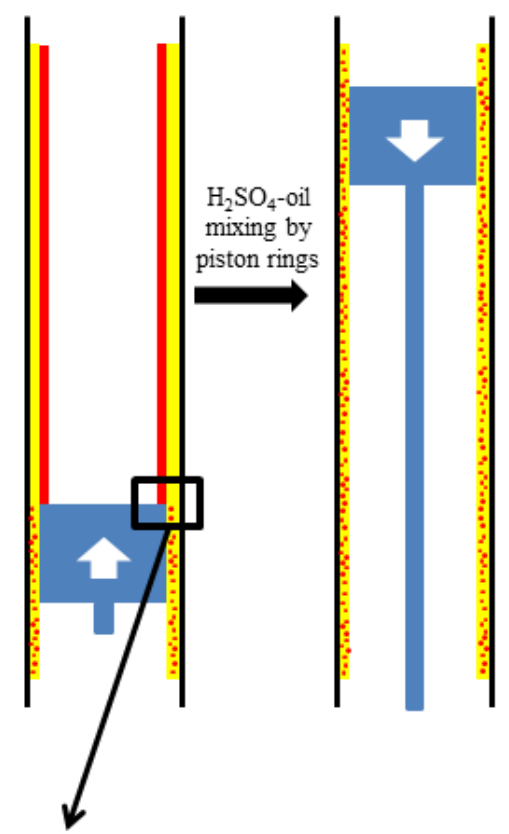

(d)

Figure 9. Illustration of lube oil dosage, $\mathrm{H}_{2} \mathrm{SO}_{4}$ droplet condensation, and mixing in an engine: (a) when the piston approaches top dead center (TDC), fresh lube oil is dosed onto the piston ring pack ${ }^{57}$ (the injection frequency of fresh lube oil is typically once every third to eighth engine revolution), (b) $\mathrm{H}_{2} \mathrm{SO}_{4}$ condenses onto the lube oil film when the piston moves towards the bottom dead center (BDC), (c) the piston moves towards TDC again, contributing to a well-mixed lube oil film where the $\mathrm{H}_{2} \mathrm{SO}_{4}$ droplets are emulsified in the lube oil, and (d) horizontal close-up of a piston ring-lube oil film, where a moving front may develop where the lube oil and $\mathrm{H}_{2} \mathrm{SO}_{4}$ droplets are effectively mixed.

From an idealized perspective, two lube oil- $\mathrm{H}_{2} \mathrm{SO}_{4}$ interaction scenarios may take place. The first scenario involves condensation of $\mathrm{H}_{2} \mathrm{SO}_{4}$ onto the lube oil film during the expansion stroke, followed by diffusion of the $\mathrm{H}_{2} \mathrm{SO}_{4}$ through the lube oil film to the cylinder liner (Figure 9(b)). In the second scenario, the $\mathrm{H}_{2} \mathrm{SO}_{4}$ droplets are fully mixed with the lube oil by the action of the piston (Figure 9(d)). In scenario 1, transport of $\mathrm{H}_{2} \mathrm{SO}_{4}$ 
through the lube oil film towards the cylinder liner takes place by droplet diffusion. The diffusion coefficient, $D_{S A}$, can be estimated by the Stokes-Einstein relation given in Eq. (4). Taking the lube oil dynamic viscosity from Sautermeister and Priest, ${ }^{47}$ and assuming that the radius of the diffusing $\mathrm{H}_{2} \mathrm{SO}_{4}$ droplets is similar to that of the MFR experiments $(0.5 \mu \mathrm{m})$, the diffusion coefficient is of the order of $10^{-12} \mathrm{~m}^{2} \mathrm{~s}^{-1}$ at $533 \mathrm{~K}$, decreasing to about $10^{-14} \mathrm{~m}^{2} \mathrm{~s}^{-1}$ at $373 \mathrm{~K}$. The mean Brownian displacement, $\bar{x}$, of a droplet after a specific time, $t$, can then be calculated by: ${ }^{46}$

$\bar{x}=\sqrt{2 D_{S A} t}$

In the diffusion scenario, the $\mathrm{H}_{2} \mathrm{SO}_{4}$ droplet has 0.5 seconds to reach the cylinder liner before the piston returns and mixes the $\mathrm{H}_{2} \mathrm{SO}_{4}$ film with the lube oil film. Within $0.5 \mathrm{~s}$, the $\mathrm{H}_{2} \mathrm{SO}_{4}$ droplet moves $1 \mu \mathrm{m}$ at $533 \mathrm{~K}$ and 0.1 $\mu \mathrm{m}$ at $373 \mathrm{~K}$, according to Eq. (25). The minimum lube oil film thickness, which is in the upper part of the cylinder, is between 2 and $5 \mu \mathrm{m}$ in a full-scale application. ${ }^{48,58}$ Unless the diffusing $\mathrm{H}_{2} \mathrm{SO}_{4}$ droplets are significantly smaller than the assumed value of $0.5 \mu \mathrm{m}$, it appears that little $\mathrm{H}_{2} \mathrm{SO}_{4}$ penetrates through the lube oil film on the cylinder liners in a film-film situation (Figure 9(b)). This finding is further supported by the fact that the lube oil is hydrophobic and the $\mathrm{H}_{2} \mathrm{SO}_{4}$ droplets hydrophilic.

The second lube oil- $\mathrm{H}_{2} \mathrm{SO}_{4}$ interaction scenario involves mixing between the $\mathrm{H}_{2} \mathrm{SO}_{4}$ film and the lube oil film by the piston rings at the moving front in front of the piston ring, Figure 9(d). Presumably, this corresponds to a situation where the $\mathrm{H}_{2} \mathrm{SO}_{4}$-lube oil film is well-mixed. In this scenario, $\mathrm{H}_{2} \mathrm{SO}_{4}$ will be present on the wall and able to interact with the cylinder liner material. Every cycle serves to mix and replenish the lube oil and $\mathrm{H}_{2} \mathrm{SO}_{4}$ locally. The residence time of a $\mathrm{H}_{2} \mathrm{SO}_{4}$ droplet on the cylinder liner is assumed to be low due to the well-mixed situation. Even though the average residence time of a lube oil film in a cylinder liner is estimated to be a couple of minutes, ${ }^{59}$ the neutralization of $\mathrm{H}_{2} \mathrm{SO}_{4}$ has to be significantly faster to avoid reaction with the cylinder liner material. In a two-stroke marine diesel engine, the piston passes by a specific point on the cylinder liner twice per revolution. If rated at $70 \mathrm{rpm}$, the time for each stroke is around $0.5 \mathrm{~s}$. The contact time for $\mathrm{H}_{2} \mathrm{SO}_{4}$ and lube oil may vary however, depending on the vertical position on the cylinder liner. In the upper part, the gas 
phase contact time with the lube oil is the longest, allowing more time for the $\mathrm{H}_{2} \mathrm{SO}_{4}$ to condense. The temperature is higher, counteracting condensation, but the pressure is also higher, thereby increasing the dew point temperature. Thus, $0.5 \mathrm{~s}$ is an important time scale for the lube oil to neutralize $\mathrm{H}_{2} \mathrm{SO}_{4}$ and prevent it from reacting with the liner material.

With these considerations, scenario 2 appears most relevant due to the extent of interaction of $\mathrm{H}_{2} \mathrm{SO}_{4}$ with the cylinder liner material. Presumably, upon mixing with the lube oil film, $\mathrm{H}_{2} \mathrm{SO}_{4}$ becomes readily emulsified due to the large excess of detergents and dispersants in the lube oil, forming a stable emulsion. Thereby, conditions locally at the liner resemble those described by the MFR model: a well-mixed lube oil volume with a constant initial Ca/S molar ratio.

An average lube oil flow feed rate to the cylinder liner can be estimated to $3.9 \cdot 10^{-7} \mathrm{~m}^{3} \mathrm{~s}^{-1}$, based on the assumption that a $30 \mathrm{MW}$ engine with 8 cylinders at 50\% load consumes $0.7 \mathrm{~g} \mathrm{kWh}^{-1}$. For typical dimensions of the cylinder liner and a lube oil thickness of $10 \mu \mathrm{m}$, an average lube oil residence time of $220 \mathrm{~s}$ is estimated, which is a value in accordance with the residence time applied in the MFR experiments. However, despite the efficient mixing caused by the piston, the full lube oil volume in a cylinder cannot be approximated as a single mixed flow reactor. In the full-scale application, the lube oil film thickness varies vertically, ${ }^{58}$ as does the $\mathrm{H}_{2} \mathrm{SO}_{4}$ condensation rate, ${ }^{56}$ because varying amounts of $\mathrm{H}_{2} \mathrm{SO}_{4}$ may condense locally on the cylinder liners. Moreover, the mathematical model can provide estimates of the degree of conversion of the condensing $\mathrm{H}_{2} \mathrm{SO}_{4}$ at confined, local points in a large two-stroke marine diesel engine. This corresponds to the discretizing of the vertical direction of the lube oil film into smaller volumes, assuming that each volume has the behavior as a mixed flow reactor. The model can then be used to predict the conversion of $\mathrm{H}_{2} \mathrm{SO}_{4}$ at specific local initial conditions, such as $\mathrm{Ca} / \mathrm{S}$ and temperature.

\subsection{Parametric study}


In the following, a parametric study is presented with the aim of investigating the adsorption-controlled neutralization reaction at conditions representative for a large two-stroke marine diesel engine. This gives an indication of how the reaction would progress in a realistic application. For this purpose, reference case simulation parameters are defined as: $T=423 \mathrm{~K}, \tau=0.5 \mathrm{~s}, f_{L, o i l, w}=0.089 \mathrm{~kg} \mathrm{~kg}^{-1}(100 \mathrm{BN})$, and $C_{S A, d}=18 \cdot 10^{3}$ mol m $\mathrm{m}^{-3}$. The remaining parameters used in the model simulations are based on the ones presented in Table 1. The effect of lube oil temperature is investigated in the range 373 to $533 \mathrm{~K}$, corresponding to the cylinder liner temperature range in a two-stroke marine diesel engine. ${ }^{3,7}$ Lube oils with different BN are used in service, depending on the sulfur content in the burned fuel, ${ }^{18}$ therefore the effect of using a $70 \mathrm{BN}$ and $140 \mathrm{BN}$ is also investigated. Depending on the operating conditions, different concentrations of the $\mathrm{H}_{2} \mathrm{SO}_{4}$ droplets can condense onto the lube oil film in a real engine application. ${ }^{56}$ The range from concentrated $\left(18 \cdot 10^{3} \mathrm{~mol} \mathrm{~m}^{-3}\right)$ to very dilute $\mathrm{H}_{2} \mathrm{SO}_{4}$ droplets $\left(1.8 \cdot 10^{3} \mathrm{~mol} \mathrm{~m}{ }^{-3}\right)$ is therefore examined. Wu et al. ${ }^{21}$ found that the shrinking rate of acid droplets depends on the lube oil formulation, i.e. different lube oils may not have an identical reaction rate constant. Therefore, the effect of varying the reaction rate constant is studied.

\subsubsection{Lube oil formulation}

Figure 10 shows the effect of the adsorption-controlled reaction rate constant and $\mathrm{H}_{2} \mathrm{SO}_{4}$ droplet radius on the conversion, with the reference case value varying by a factor of 5 . Increasing $k_{a d s}$ by a factor of 5 corresponds to decreasing $R_{S A}$ by a factor of 5. A significant adverse effect is observed when decreasing $k_{a d s}$ (increasing $R_{S A}$ ). It shows that in order to enhance the performance of a specific lube oil with respect to neutralization, the oil should be formulated to increase the adsorption rate of reverse micelles onto $\mathrm{H}_{2} \mathrm{SO}_{4}$ droplets, i.e. increase the adsorption-controlled reaction rate constant. The simulations also suggest that the lube oil should be formulated with surfactants capable of emulsifying the $\mathrm{H}_{2} \mathrm{SO}_{4}$ sufficiently. If $\mathrm{H}_{2} \mathrm{SO}_{4}$ is poorly emulsified in the lube oil, resulting in enlarged droplets, significant amounts of $\mathrm{H}_{2} \mathrm{SO}_{4}$ may reach the cylinder liner material. 

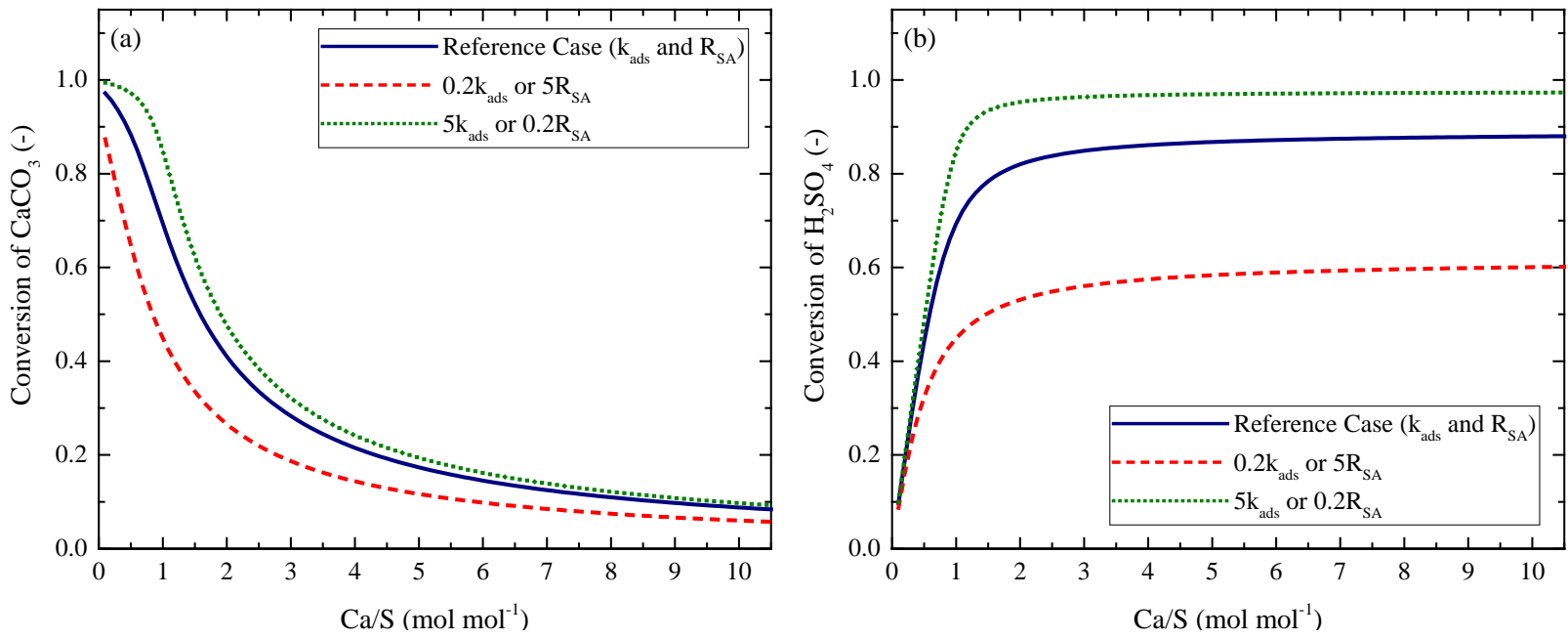

Figure 10. Model simulations showing conversion of (a) $\mathrm{CaCO}_{3}$ reverse micelles and (b) $\mathrm{H}_{2} \mathrm{SO}_{4}$ droplets as a function of $\mathrm{Ca} / \mathrm{S}$ at three values of $k_{a d s}$ and $R_{S A}$, respectively. Model parameters are: $T=423 \mathrm{~K}, \tau=0.5 \mathrm{~s}$, $f_{L, o i l, w}=0.089 \mathrm{~kg} \mathrm{~kg}^{-1}(100 \mathrm{BN}), C_{S A, d}=18 \cdot 10^{3} \mathrm{~mol} \mathrm{~m}^{-3}$, as well as those in Table 1.

\subsubsection{Base number}

An important property of the lube oil is the base number (BN, i.e. $\mathrm{CaCO}_{3}$ concentration). The effect of varying the $\mathrm{BN}$ in the lube oil is shown in Figure 11. The volumetric inlet flow rate, $v_{o i l, f}$, is kept unchanged when altering the $\mathrm{BN}$ of lube oil. The weight fraction of $\mathrm{CaCO}_{3}$ in the lube oil, $f_{L, o i l, w}$, is changed, affecting the number of micelles in the inlet lube oil (Eq. (20)), $N_{L, f}$, and also the $\mathrm{H}_{2} \mathrm{SO}_{4}$ droplet flow to the lube oil volume (Eq. (22)), $F_{S A}$. Figure 11 shows that the conversion of $\mathrm{H}_{2} \mathrm{SO}_{4}$ increases slightly with the BN of the lube oil at a constant $\mathrm{Ca} / \mathrm{S}$ molar ratio. For a $\mathrm{Ca} / \mathrm{S}$ equal to 1 , the conversion increases by $5 \%$ when increasing the lube oil $\mathrm{BN}$ from $100 \mathrm{BN}$ to $140 \mathrm{BN}$, and decreases by 6\% when switching a $100 \mathrm{BN}$ lube oil to $70 \mathrm{BN}$ lube oil. This is due to the higher concentrations of $\mathrm{CaCO}_{3}$ and $\mathrm{H}_{2} \mathrm{SO}_{4}$, resulting in an increase in the reaction rate. The results indicate that it could be beneficial to use a higher BN lube oil, in combination with a decreased lube oil feed rate (maintained $\mathrm{Ca} / \mathrm{S}$ value). However, it is a trade-off because a reduced oil feed rate may lead to exposure of the liner surface and insufficient lubrication leading to e.g. scuffing. 

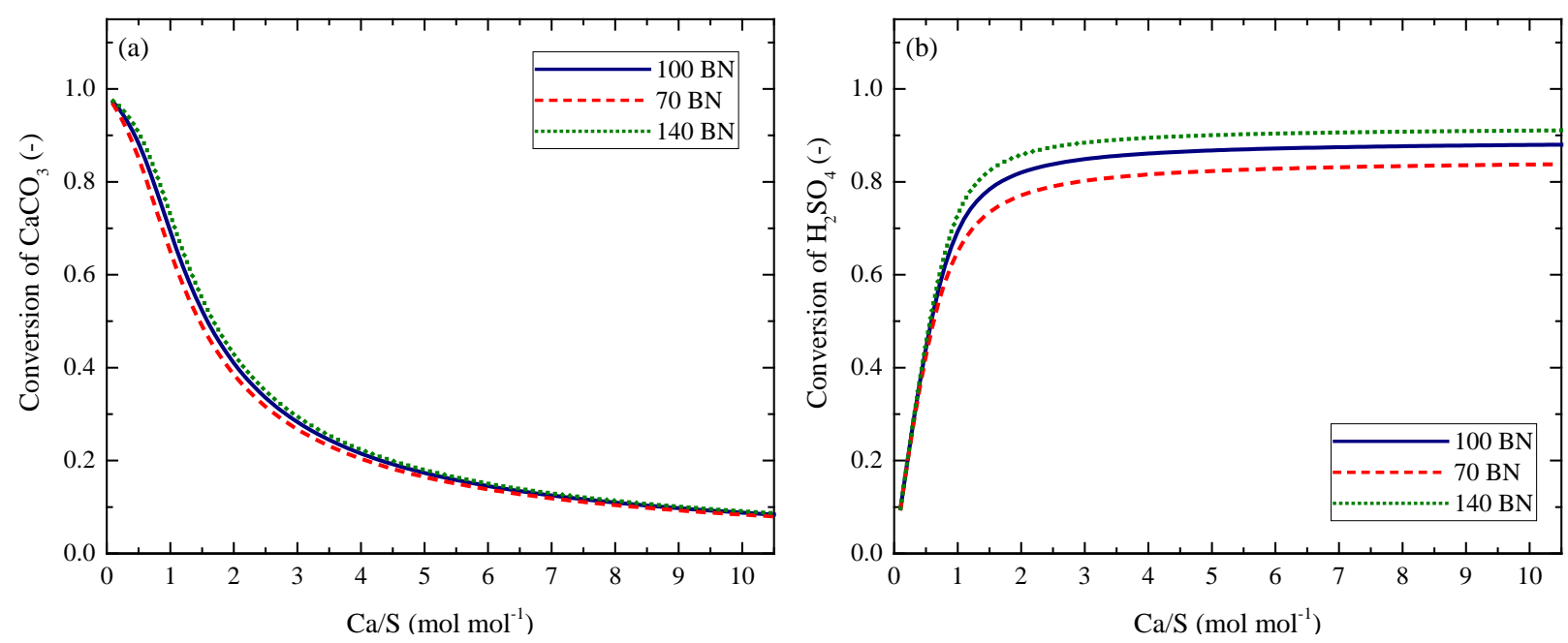

Figure 11. Model simulations showing conversion of (a) $\mathrm{CaCO}_{3}$ reverse micelles and (b) $\mathrm{H}_{2} \mathrm{SO}_{4}$ droplets as a function of $\mathrm{Ca} / \mathrm{S}$ at three values of the base number of the lube oil. Model parameters are: $R_{S A}=0.5 \mu \mathrm{m}, T=$ $423 \mathrm{~K}, \tau=0.5 \mathrm{~s}, C_{S A, d}=18 \cdot 10^{3} \mathrm{~mol} \mathrm{~m}{ }^{-3}$, as well as those in Table 1.

\subsubsection{Concentration of $\mathrm{H}_{2} \mathrm{SO}_{4}$ droplets}

The effect of varying the concentration of the $\mathrm{H}_{2} \mathrm{SO}_{4}$ droplets is investigated in Figure 12 . At a $\mathrm{Ca} / \mathrm{S}$ molar ratio equal to 1 , the conversion of $\mathrm{H}_{2} \mathrm{SO}_{4}$ increases by $10 \%$ and $23 \%$ respectively, when diluting the $\mathrm{H}_{2} \mathrm{SO}_{4}$ droplet concentration by factors of 5 and 10 compared to the reference value. When the $\mathrm{H}_{2} \mathrm{SO}_{4}$ droplet concentration decreases, the $\mathrm{H}_{2} \mathrm{SO}_{4}$ droplet flow, $F_{S A}$, is increased to maintain a constant $\mathrm{Ca} / \mathrm{S}$ molar ratio. The number of $\mathrm{H}_{2} \mathrm{SO}_{4}$ droplets emulsified into the lube oil film is thereby increased, but they are more dilute. This leads to an increase in reaction rate according to Eq. (11), and consequently a higher conversion is found for decreasing $\mathrm{H}_{2} \mathrm{SO}_{4}$ droplet concentration. However, the effect is minor compared to that of changing $k_{a d s}$ and $R_{S A}$ (Figure 10). 

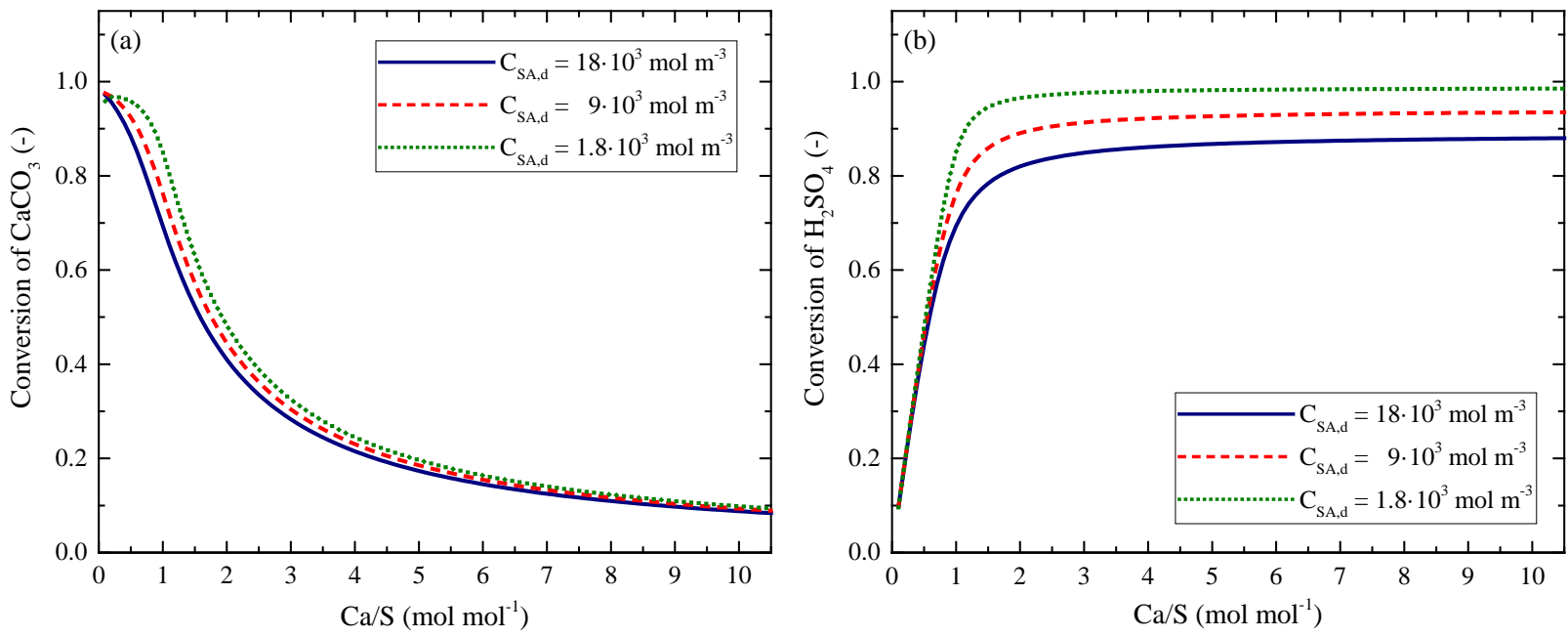

Figure 12. Model simulations showing conversion of (a) $\mathrm{CaCO}_{3}$ reverse micelles and (b) $\mathrm{H}_{2} \mathrm{SO}_{4}$ droplets as a function of $\mathrm{Ca} / \mathrm{S}$ at three values of $\mathrm{H}_{2} \mathrm{SO}_{4}$ droplet concentration. Model parameters are: $R_{S A}=0.5 \mu \mathrm{m}, T=423$ $\mathrm{K}, \tau=0.5 \mathrm{~s}, f_{L, o i l, w}=0.089 \mathrm{~kg} \mathrm{~kg}^{-1}(100 \mathrm{BN})$, as well as those in Table 1.

The simulations in Figure 12 show an opposite effect of decreased $\mathrm{H}_{2} \mathrm{SO}_{4}$ concentration as compared to the MFR experiments, where a decrease in $\mathrm{H}_{2} \mathrm{SO}_{4}$ concentration from $18 \cdot 10^{3} \mathrm{~mol} \mathrm{~m} \mathrm{~m}^{-3}$ to $5 \cdot 10^{3} \mathrm{~mol} \mathrm{~m}^{-3}$ led to a small reduction in conversion. ${ }^{38}$ However, significantly more water was introduced in the MFR experiments when decreasing the $\mathrm{H}_{2} \mathrm{SO}_{4}$ concentration and maintaining the $\mathrm{Ca} / \mathrm{S}$ molar ratio. This may have reduced the solubilization of the $\mathrm{H}_{2} \mathrm{SO}_{4}$ droplets due to a limited amount of excess of dispersants and detergents in the lube oil, resulting in enlarged droplets. As shown in Figure 8, larger $\mathrm{H}_{2} \mathrm{SO}_{4}$ droplets result in a reduction in the conversion. The isolated effect of changing the $\mathrm{H}_{2} \mathrm{SO}_{4}$ droplet concentration may therefore be difficult to assess experimentally. Another explanation for the difference between experimental and modeling results could lie in the assumption of the model that the adsorption rate constant, $k_{a d s}$, does not depend on the $\mathrm{H}_{2} \mathrm{SO}_{4}$ droplet concentration. Duan et al. ${ }^{53}$ show that the shrinking rate $\left(d R_{S A} / d t\right)$ of acetic acid droplets in fully formulated passenger-car lube oil decreases when decreasing the acetic acid droplet concentration. Also, Fu et al. ${ }^{26}$ report that the shrinking rate of a droplet of pure water is about one magnitude lower than that of an $\mathrm{H}_{2} \mathrm{SO}_{4}$ droplet. This suggests that the shrinking rate depends on the nature, chemical interaction, and concentration of the 
droplets. Local condensation of strongly diluted $\mathrm{H}_{2} \mathrm{SO}_{4}$ droplets will increase the water content of the lube oil emulsion. This could possibly lead to disruption of the lube oil film and direct $\mathrm{H}_{2} \mathrm{SO}_{4}$-metal contact, causing accelerated corrosion of the cylinder liner material, ${ }^{60,61}$ especially at a low $\mathrm{Ca} / \mathrm{S}$ molar ratio (Figure $\mathrm{S} 1$ in Supporting Information).

\subsubsection{Residence time}

The effect of reaction time is investigated in Figure 13. It is done by fixing the volume of the lube oil film and only changing the volumetric inlet lube oil flow rate, $v_{\text {oil }, f}$. The conversion increases with residence time, as expected. At a Ca/S equal to 1, the conversion decreases by $35 \%$ when decreasing the residence time from 0.5 seconds to 0.1 seconds, and increases $22 \%$ when increasing the residence time from 0.5 seconds to 2.5 seconds. In the MFR experiments, no effect of residence time in the range from 48 seconds to 210 seconds at $\mathrm{Ca} / \mathrm{S} \mathrm{molar}$ ratios around 1.4 and 2.0 was found. ${ }^{38}$ However, the model predicts an increase in the conversion of $\mathrm{CaCO}_{3}$ by $17 \%$ at $\mathrm{Ca} / \mathrm{S}=1.4$, when the residence time is increased from 48 seconds to 210 seconds in the MFR (Figure S2 in Supporting Information).
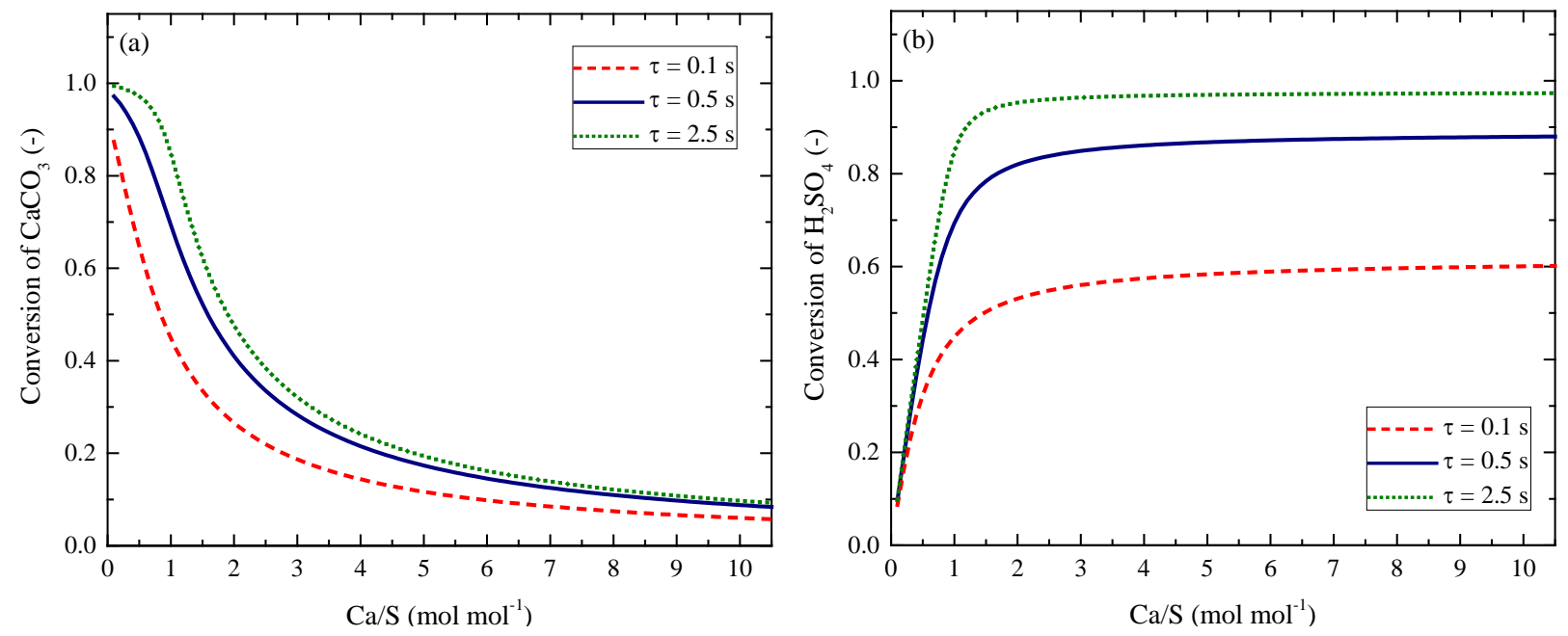

Figure 13. Model simulations showing conversion of (a) $\mathrm{CaCO}_{3}$ reverse micelles and (b) $\mathrm{H}_{2} \mathrm{SO}_{4}$ droplets as a function of $\mathrm{Ca} / \mathrm{S}$ at three values of lube oil film residence time. Model parameters are: $R_{S A}=0.5 \mu \mathrm{m}, T=423$ $\mathrm{K}, f_{L, o i l, w}=0.089 \mathrm{~kg} \mathrm{~kg}^{-1}(100 \mathrm{BN}), C_{S A, d}=18 \cdot 10^{3} \mathrm{~mol} \mathrm{~m}^{-3}$, as well as those in Table 1. 
In Figure 14, the conversion of $\mathrm{CaCO}_{3}$ (Figure 14(a)) and $\mathrm{H}_{2} \mathrm{SO}_{4}$ (Figure 14(b)) is shown as a function of residence time for three different $\mathrm{Ca} / \mathrm{S}$ molar ratios. According to the predictions, the neutralization is initially very fast at engine conditions. This is in agreement with the findings of Roman ${ }^{35}$ who performed stirred, thin lube oil film batch reactor experiments with a Ca/S molar ratio of around 0.5, a $100 \mathrm{BN}$ lube oil, and a temperature of $373 \mathrm{~K}$. He concluded that the reaction is extremely rapid and takes place within only a few seconds before reaching a plateau with a significantly reduced reaction rate. Modeling simulations for the same conditions as those of Roman, indicate a $50 \%$ conversion of $\mathrm{CaCO}_{3}$ within 0.4 seconds, while $90 \%$ conversion is achieved for a residence time of 5 seconds. These values are roughly in agreement with the ones given by Roman. ${ }^{35}$
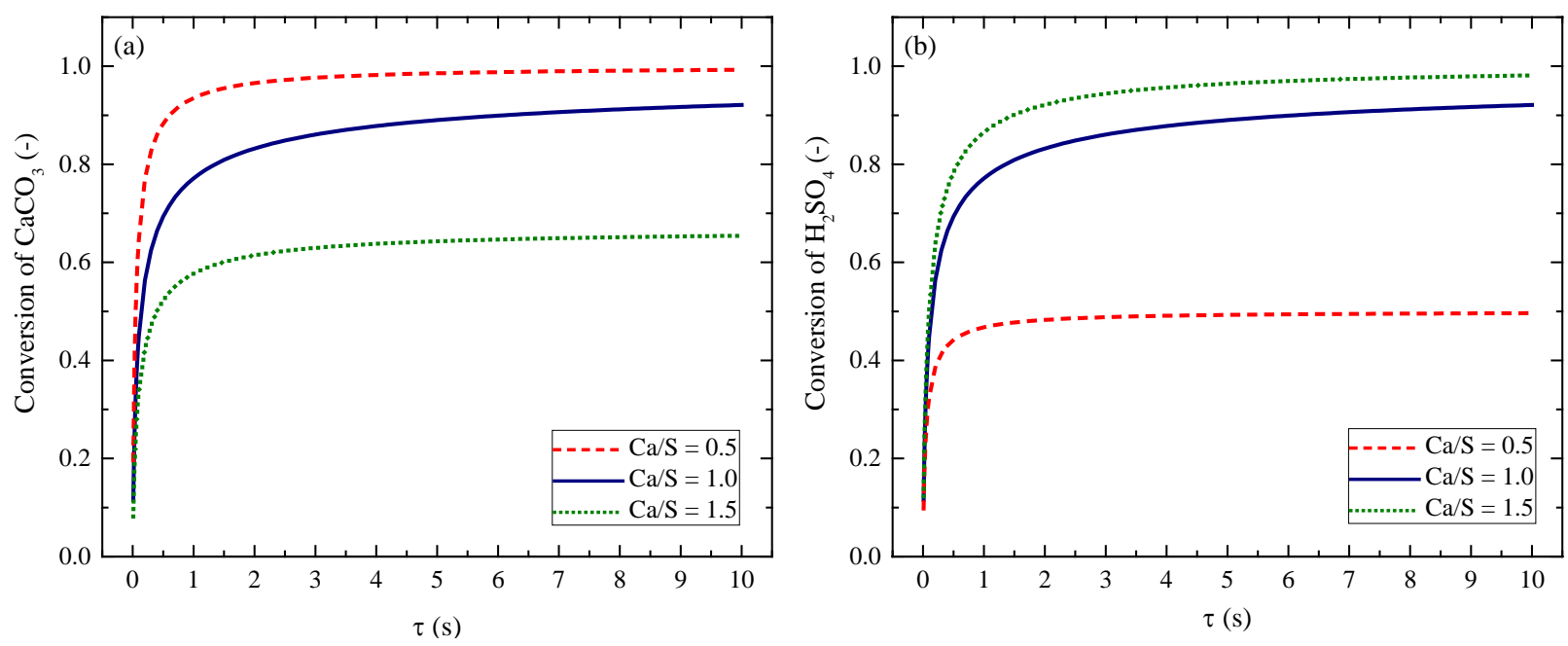

Figure 14. Model simulations showing conversion of (a) $\mathrm{CaCO}_{3}$ reverse micelles and (b) $\mathrm{H}_{2} \mathrm{SO}_{4}$ droplets as a function of residence time at three values of $\mathrm{Ca} / \mathrm{S}$. Model parameters are: $R_{S A}=0.5 \mu \mathrm{m}, T=423 \mathrm{~K}, f_{L, o i l, w}=$ $0.089 \mathrm{~kg} \mathrm{~kg}^{-1}(100 \mathrm{BN}), C_{S A, d}=18 \cdot 10^{3} \mathrm{~mol} \mathrm{~m}^{-3}$, as well as those in Table 1.

\subsubsection{Lube oil temperature}


The effect of the lube oil temperature in the range $373 \mathrm{~K}$ to $533 \mathrm{~K}$ is investigated in Figure 15 . The model predicts a significant effect of temperature on conversion. The $\mathrm{H}_{2} \mathrm{SO}_{4}$ is almost fully neutralized after 0.5 seconds when the temperature is higher than $473 \mathrm{~K}$ and $\mathrm{Ca} / \mathrm{S}>1$ (Figure $15(\mathrm{~b})$ ). For instance, $92.5 \% \mathrm{H}_{2} \mathrm{SO}_{4}$ is neutralized after 0.5 seconds at $533 \mathrm{~K}$ at $\mathrm{Ca} / \mathrm{S}=1$. When $\mathrm{H}_{2} \mathrm{SO}_{4}$ is in great excess (e.g. $\mathrm{Ca} / \mathrm{S}=0.1$ ), the $\mathrm{CaCO} 3$ is almost completely depleted locally at these temperatures.

At $373 \mathrm{~K}$, i.e. the lower end of the liner temperature in a two-stroke marine diesel engine, ${ }^{7}$ a significant fraction of the $\mathrm{H}_{2} \mathrm{SO}_{4}$ is not neutralized, and the $\mathrm{H}_{2} \mathrm{SO}_{4}$ has the potential of interacting with the cylinder liner surface during the stagnant period until the next mixing stroke.
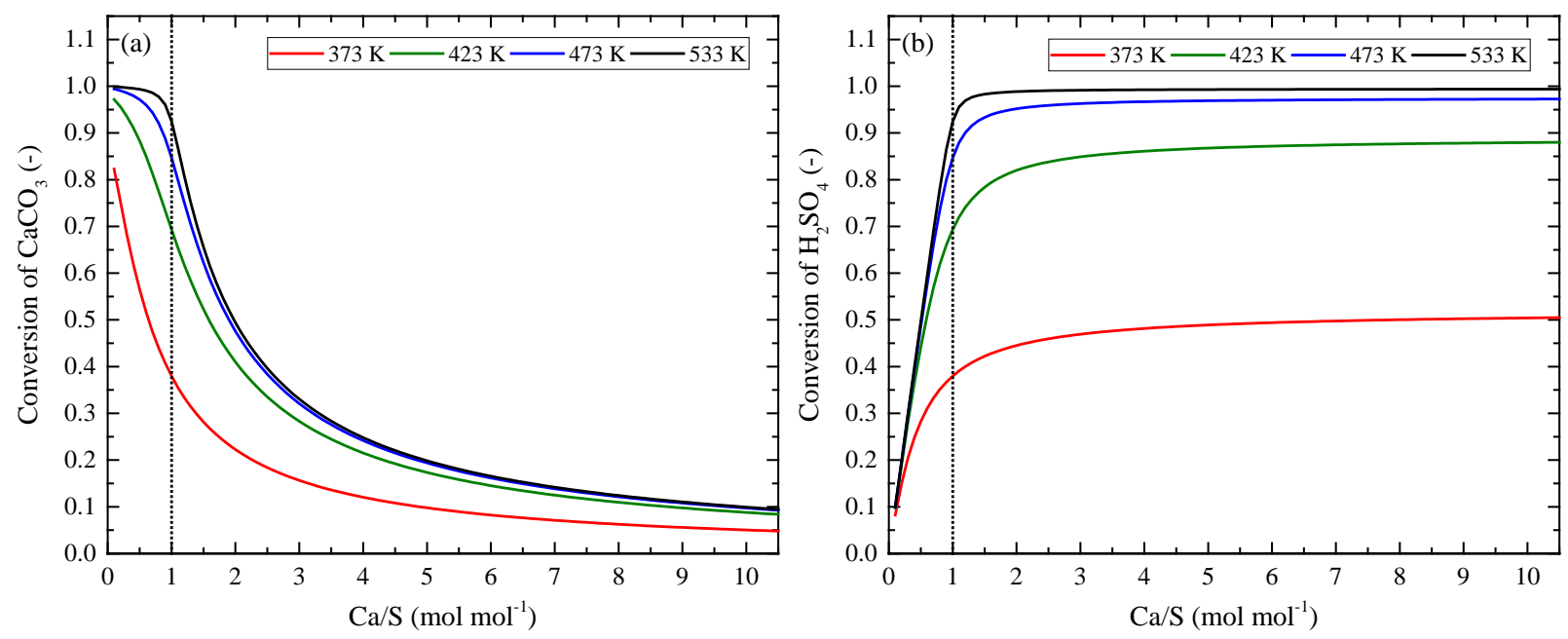

Figure 15. Model simulations showing conversion of (a) $\mathrm{CaCO}_{3}$ reverse micelles and (b) $\mathrm{H}_{2} \mathrm{SO}_{4}$ droplets as a function of $\mathrm{Ca} / \mathrm{S}$ at varying temperature between $373 \mathrm{~K}$ and $533 \mathrm{~K}$. Model parameters are: $R_{S A}=0.5 \mu \mathrm{m}, \tau=$ $0.5 \mathrm{~s}, f_{L, o i l, w}=0.089 \mathrm{~kg} \mathrm{~kg}^{-1}(100 \mathrm{BN}), C_{S A, d}=18 \cdot 10^{3} \mathrm{~mol} \mathrm{~m}^{-3}$, as well as those in Table 1 . The vertical dotted line represents $\mathrm{Ca} / \mathrm{S}=1$.

By use of Eq. (6), it is possible to calculate the average concentration of $\mathrm{H}_{2} \mathrm{SO}_{4}$ in the lube oil film emulsion after 0.5 seconds of reaction time after mixing by the passing piston rings, and thereby also at the cylinder liner surface during the stagnant time period, see Figure 16. The $\mathrm{H}_{2} \mathrm{SO}_{4}$ concentration increases dramatically for $\mathrm{Ca} / \mathrm{S}<1$, showing that it is important to avoid a local excess of $\mathrm{H}_{2} \mathrm{SO}_{4}$ compared to $\mathrm{CaCO}_{3}$ on the cylinder liner 
surface, in order to minimize corrosion and wear of the cylinder liner and piston rings. The concentration of $\mathrm{H}_{2} \mathrm{SO}_{4}$ decreases with increasing lube oil temperature, as expected from Figure 15. The results of Figs. 15 and 16 indicate that the $\mathrm{H}_{2} \mathrm{SO}_{4}$ is likely to reach the cylinder liner surface no matter how well lubricated the surface is. However, a certain degree of corrosion may be beneficial in order to maintain a rough cylinder liner surface for supporting a lube oil film. ${ }^{11}$

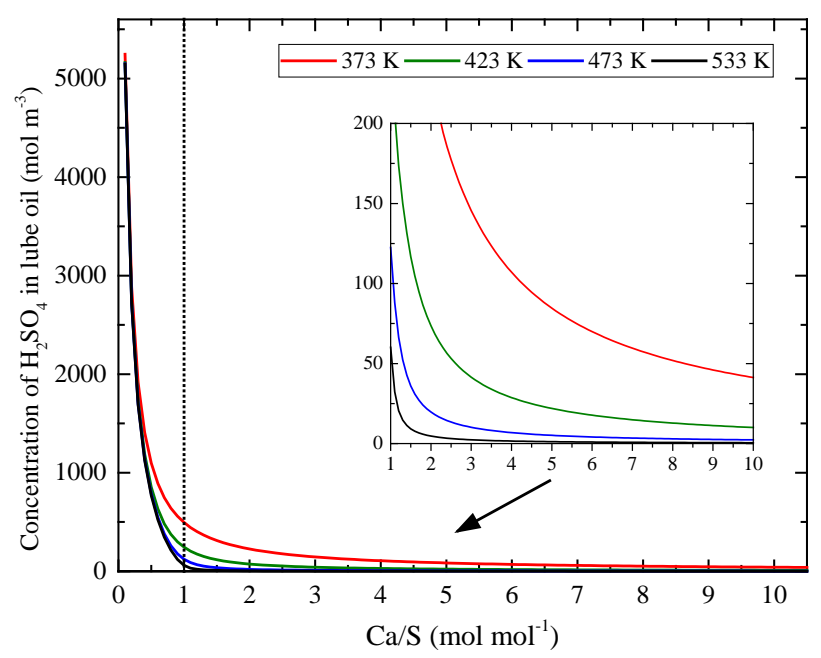

Figure 16. Model simulations showing the average concentration of $\mathrm{H}_{2} \mathrm{SO}_{4}$ in the lube oil film as a function of $\mathrm{Ca} / \mathrm{S}$ at varying temperatures between $373 \mathrm{~K}$ and $533 \mathrm{~K}$. Model parameters are: $R_{S A}=0.5 \mu \mathrm{m}, \tau=0.5 \mathrm{~s}, f_{L, o i l, w}$ $=0.089 \mathrm{~kg} \mathrm{~kg}^{-1}(100 \mathrm{BN}), C_{S A, d}=18 \cdot 10^{3} \mathrm{~mol} \mathrm{~m}^{-3}$, as well as those in Table 1 . The vertical dotted line represents $\mathrm{Ca} / \mathrm{S}=1$.

\subsection{Practical implications}

The parametric study indicates that the neutralization of $\mathrm{H}_{2} \mathrm{SO}_{4}$ and the interaction of $\mathrm{H}_{2} \mathrm{SO}_{4}$ with the liner surface is a complex function of: lube oil formulation; flow pattern at the cylinder liner (mixing behavior); and vertical, local position at the cylinder liner (which affects lube oil temperature, residence time, and concentration of condensing $\mathrm{H}_{2} \mathrm{SO}_{4}$ ). The upper part of the cylinder liner is the segment where the most severe wear is found. ${ }^{3,62}$ In this section, possible factors affecting the presence of $\mathrm{H}_{2} \mathrm{SO}_{4}$ at the liner surface in the upper region are discussed. 
The cylinder liner temperature in the upper part is high. ${ }^{1}$ Consequently, a decrease in $\mathrm{H}_{2} \mathrm{SO}_{4}$ condensation rate would be expected, ${ }^{56}$ and the neutralization reaction would be fast (Figure 16), both ultimately contributing to a reduction in wear. ${ }^{1,3}$ However, the pressure in the cylinder liner is highest when the piston is near top dead center (TDC) upon combustion (thus $\mathrm{SO}_{3} / \mathrm{H}_{2} \mathrm{SO}_{4}$ partial pressures are highest near TDC), resulting in a high dew point temperature of $\mathrm{H}_{2} \mathrm{SO}_{4}(\mathrm{aq})$, in this area. ${ }^{3}$ Furthermore, the upper part of the cylinder is exposed to the combustion gas for the longest length of time. ${ }^{7}$ Despite the higher temperature, most of the $\mathrm{H}_{2} \mathrm{SO}_{4}$ formed from oxidation of the fuel-sulfur may thus condense on the upper part of the cylinder liner segment, as reported. ${ }^{7,56} \mathrm{~A}$ high load of $\mathrm{H}_{2} \mathrm{SO}_{4}$ in the lube oil in this region could also be facilitated by the upward motion of the piston, collecting the condensed $\mathrm{H}_{2} \mathrm{SO}_{4}$ above the top piston ring. ${ }^{26}$ The upper part of the cylinder is also the area where the piston speed is the lowest, ${ }^{1}$ decreasing the degree of mixing of the lube oil film, and the lube oil film thickness is at its minimum. ${ }^{58} \mathrm{~A}$ local excess of $\mathrm{H}_{2} \mathrm{SO}_{4}$ compared to $\mathrm{CaCO}_{3}$ in the upper part of the cylinder liner would explain the corrosive wear that has been observed. In addition, more water is known to condense in the upper part of the cylinder, ${ }^{7}$ increasing the risk of direct $\mathrm{H}_{2} \mathrm{SO}_{4}$-liner contact through disruption of the lube oil film..$^{60,61}$

One method to reduce the wear would be to increase the flow rate of lube oil and thereby the local $\mathrm{Ca} / \mathrm{S}$ molar ratio in the upper segment. For a constant thickness of the lube oil film, the average residence time depends on the engine load and the feed rate of lube oil. When increasing the feed rate and the engine load, the average residence time decreases. ${ }^{3,63}$ However, at the same time, more $\mathrm{CaCO}_{3}$ is introduced, increasing the $\mathrm{Ca} / \mathrm{S}$ molar ratio. The effect of increasing $\mathrm{Ca} / \mathrm{S}$ is considerable when $\mathrm{Ca} / \mathrm{S}<1.5$, according to Figure 15 . A lower engine load leads to a lower piston velocity, thus increasing the exposure time between lube oil and $\mathrm{H}_{2} \mathrm{SO}_{4}$. This gives more time for the neutralization reaction to occur, but it also gives more time for non-neutralized $\mathrm{H}_{2} \mathrm{SO}_{4}$ in the lube oil emulsion to react with the cylinder liner material at stagnant conditions. The $\mathrm{Ca} / \mathrm{S}$ molar ratio can also be increased by using higher BN lube oil. According to the present work, this would lead to a slightly faster 
neutralization of $\mathrm{H}_{2} \mathrm{SO}_{4}$, thereby decreasing the contact between $\mathrm{H}_{2} \mathrm{SO}_{4}$ and the liner and consequently the corrosion. This is in accordance to experiences from service. ${ }^{1}$

The above analysis shows that the prevention of cold corrosion is a complex challenge. $\mathrm{H}_{2} \mathrm{SO}_{4}$ will be present at the cylinder liner surface to some degree regardless of how well-lubricated the surface is. It is therefore more a matter of how much $\mathrm{H}_{2} \mathrm{SO}_{4}$ can be neutralized in the shortest period of time, in order to prevent undesired corrosion in the large two-stroke marine diesel engines.

\section{Conclusions}

The reaction between $\mathrm{H}_{2} \mathrm{SO}_{4}$ droplets and $\mathrm{CaCO}_{3}$ micelles in lube oil has been studied in a well-mixed flow reactor and a batch reactor at $\mathrm{Ca} / \mathrm{S}$ molar ratios, relevant for a real engine application. The purpose was to isolate the rate-limiting step(s) of the neutralization mechanism. For the residence times investigated, the results showed that the reactant conversion was significantly reduced when the $\mathrm{Ca} / \mathrm{S}$ molar ratio approached unity. It was also found, that a certain degree of stirring is required to establish contact between $\mathrm{H}_{2} \mathrm{SO}_{4}$ droplets and $\mathrm{CaCO}_{3}$ reverse micelles in order to initiate and maintain the reaction, probably to effectively emulsify $\mathrm{H}_{2} \mathrm{SO}_{4}$ into the lube oil. The experiments performed in the MFR and batch reactor suggest that the rate-limiting step in the neutralization mechanism is the adsorption of $\mathrm{CaCO}_{3}$ reverse micelles onto the $\mathrm{H}_{2} \mathrm{SO}_{4}$ droplets. A mathematical model for the neutralization of $\mathrm{H}_{2} \mathrm{SO}_{4}$ droplets by $\mathrm{CaCO}_{3}$ reverse micelles lube oil under mixedflow conditions has been developed and was verified by using mixed flow reactor experimental data obtained by the authors. The results support adsorption as the rate-controlling step in the neutralization mechanism. The mixed flow reactor model offers a useful approximation to conditions in the lube oil film on the cylinder liner, and can be used to assess the importance of different process parameters. The neutralization reaction rate increases significantly with the lube oil temperature, while the lube oil base number and the $\mathrm{H}_{2} \mathrm{SO}_{4}$ droplet concentration have only a minor impact at a maintained $\mathrm{Ca} / \mathrm{S}$ molar ratio. Modeling predictions indicate that $\mathrm{H}_{2} \mathrm{SO}_{4}$ will be present to some degree on the cylinder liner surface independent of how well-wetted the liner is. 
The concentration of $\mathrm{H}_{2} \mathrm{SO}_{4}$ in the lube oil film is significantly increased for conditions with a local molar excess of $\mathrm{H}_{2} \mathrm{SO}_{4}$, compared to $\mathrm{CaCO}_{3}$ micelles $(\mathrm{Ca} / \mathrm{S}<1)$. To control the corrosion rate, it is important to ensure that sufficient lube oil is provided in critical regions, particularly at the upper part of the cylinder liner where the most pronounced wear is most often found. Both the derived adsorption kinetics, which can be used in computational fluid dynamics (CFD) models and the mathematical model, are expected to facilitate further studies to understand and control corrosion and wear in large two-stroke marine diesel engines. By connecting the knowledge of where $\mathrm{H}_{2} \mathrm{SO}_{4}$ is condensing ${ }^{56,64}$ with how it is neutralized (the present article), it may be possible to optimize the spatial lube oil dosage onto the cylinders to counteract severe corrosive wear.

\author{
AUTHOR INFORMATION

\section{Corresponding Author} \\ *E-mail: sk@kt.dtu.dk
}

Supporting Information. Table S1, Experimental MFR conditions; Figure S1, Simulated ratio between outlet and inlet flow rates at varying $\mathrm{H}_{2} \mathrm{SO}_{4}$ droplet concentrations; Figure S2, Simulated residence time variation on $\mathrm{CaCO}_{3}$ conversion for MFR conditions.

This information is available free of charge via the Internet at http://pubs.acs.org/.

\title{
ACKNOWLEDGEMENTS
}

This work is part of the Combustion and Harmful Emission Control (CHEC) research center at the Department of Chemical and Biochemical Engineering at the Technical University of Denmark. The project is funded by the 
Innovation Fund Denmark and co-sponsored by MAN Energy Solutions and the Technical University of Denmark through the SULCOR project under grant 4106-00028B.

\section{Nomenclature}

$A_{i}=$ Surface area of component $i\left(4 \pi R_{i}^{2}\right)\left[\mathrm{m}^{2}\right]$

$B N=$ Base number $\left[(\mathrm{mg} \mathrm{KOH})\left(\right.\right.$ g oil $\left.^{-1}\right]$

$\mathrm{Ca} / \mathrm{S}=$ Molar ratio of $\mathrm{CaCO}_{3}$ to $\mathrm{H}_{2} \mathrm{SO}_{4}$ in inlet feed [mol mol${ }^{-1}$ ]

$C_{i}=$ Concentration of component $i\left[\mathrm{~mol} \mathrm{~m}^{-3}\right]$

$C_{S A, d}=$ Concentration of $\mathrm{H}_{2} \mathrm{SO}_{4}$ in droplets $\left[\mathrm{mol} \mathrm{m}^{-3}\right.$ ]

$d_{c}=$ Critical distance where immediate reaction occurs [m]

$D_{i}=$ Diffusion coefficient of component $i\left[\mathrm{~m}^{2} \mathrm{~s}^{-1}\right]$

$E_{a}=$ Activation energy $\left[\mathrm{J} \mathrm{mol}^{-1}\right]$

$F_{S A}=\mathrm{H}_{2} \mathrm{SO}_{4}$ droplet number flow [(number of droplets) $\mathrm{s}^{-1}$ ]

$f_{\mathrm{L}}=$ Volume fraction of $\mathrm{CaCO}_{3}$ in reverse micelle $\left[\mathrm{m}^{3} \mathrm{~m}^{-3}\right]$

$f_{\mathrm{L}, o i l, w}=$ Weight fraction of $\mathrm{CaCO}_{3}$ in lube oil $\left[\mathrm{kg} \mathrm{kg}^{-1}\right]$

$i=$ Component $i[-]$

$k_{a d s}=$ Adsorption-controlled reaction rate constant $\left[\mathrm{m} \mathrm{s}^{-1}\right]$

$k_{a d s}^{\prime}=$ Adsorption-controlled reaction rate constant $\left[\mathrm{m}^{3} \mathrm{~mol}^{-1} \mathrm{~s}^{-1}\right]$

$k_{B}=$ Boltzmann constant, $1.38 \cdot 10^{-23}\left[\mathrm{~kg} \mathrm{~m}^{2} \mathrm{~s}^{-2} \mathrm{~K}^{-1}\right]$

$k_{\text {diff }}=$ Diffusion-controlled reaction rate constant $\left[\mathrm{m}^{3} \mathrm{~mol}^{-1} \mathrm{~s}^{-1}\right]$

$k_{\text {res }}=$ Resulting reaction rate constant $\left[\mathrm{m}^{3} \mathrm{~mol}^{-1} \mathrm{~s}^{-1}\right]$

$M_{i}=$ Molar weight of component $i\left[\mathrm{~kg} \mathrm{~mol}^{-1}\right]$

$N=$ Stirrer speed $[\mathrm{rpm}]$

$N_{A}=$ Avogadro's constant, $6.022 \cdot 10^{23}$ [molecules mol ${ }^{-1}$ ] 
$n_{i}=$ Moles of component i [mol]

$N_{i}=$ Number of component $i$ per volume [number $\mathrm{m}^{-3}$ ]

$N_{i, f}=$ Number of component $i$ per volume in inlet feed [number $\mathrm{m}^{-3}$ ]

$n_{\mathrm{L}}=$ Moles of $\mathrm{CaCO}_{3}$ per reverse micelle $[\mathrm{mol}]$

$-r_{A, i}=$ Reaction rate $\left[\mathrm{mol} \mathrm{m} \mathrm{m}^{-3} \mathrm{~s}^{-1}\right]$

$R=$ Ideal gas constant, $8.314\left[\mathrm{~J} \mathrm{~mol}^{-1} \mathrm{~K}^{-1}\right]$

$R_{i}=$ Radius of component $i[\mathrm{~m}]$

$t=$ Time $[\mathrm{s}]$

$T=$ Temperature in lube oil volume $[\mathrm{K}]$

$V_{i}=$ Average volume of component $i\left(4 / 3 \pi R_{i}^{3}\right)\left[\mathrm{m}^{3}\right]$

$v_{i, f}=$ Volumetric feed rate of component $i\left[\mathrm{~m}^{3} \mathrm{~s}^{-1}\right]$

$v_{o}=$ Volumetric outflow of lube oil emulsion $\left[\mathrm{m}^{3} \mathrm{~s}^{-1}\right]$

$V_{\text {oil }}=$ Volume of lube oil in mixed flow reactor $\left[\mathrm{m}^{3}\right]$

$\bar{x}=$ Mean Brownian displacement of a particle [m]

$X_{\mathrm{i}}=$ Conversion of component $i[-]$

\section{Greek Letters}

$\eta=$ Lube oil dynamic viscosity $\left[\mathrm{kg} \mathrm{m}^{-1} \mathrm{~s}^{-1}\right]$

$\theta=$ Fraction of surface that is occupied [-]

$\rho_{i}=$ Density of component $i\left[\mathrm{~kg} \mathrm{~m}^{-3}\right]$

$\tau=$ Residence time $[\mathrm{s}]$

Subscripts

ads = Adsorption-controlled 


$$
\begin{aligned}
& \text { diff = Diffusion-controlled } \\
& \mathrm{d}=\text { Droplet } \\
& \mathrm{f}=\text { Inlet feed } \\
& \mathrm{L}=\text { Limestone, } \mathrm{CaCO}_{3} \text { or } \mathrm{CaCO}_{3} \text { reverse micelle } \\
& \text { o = Outlet } \\
& \text { Oil = Lube oil } \\
& \text { SA = Sulfuric acid, } \mathrm{H}_{2} \mathrm{SO}_{4} \text { or } \mathrm{H}_{2} \mathrm{SO}_{4} \text { droplet } \\
& \text { w = weight }
\end{aligned}
$$

\section{REFERENCES}

(1) CIMAC Working Group 8 "Marine Lubricants.” CIMAC Guideline Cold Corrosion in Marine Two Stroke Engines. 2017.

(2) MAN Diesel \& Turbo. Service Letter SL2014-587/JAP. 2014.

(3) García, L.; Gehle, S.; Schakel, J. Impact of Low Load Operation in Modern Low Speed 2-Stroke Diesel Engines on Cylinder Liner Wear Caused by Increased Acid Condensation. J. JIME 2014, 49 (1), 100106.

(4) Cordtz, R. L.; Schramm, J.; Rabe, R. Investigating $\mathrm{SO}_{3}$ Formation from the Combustion of Heavy Fuel Oil in a Four-Stroke Medium Speed Test Engine. Energy Fuels 2013, 27 (10), 6279-6286.

(5) Adamkiewicz, A.; Drzewieniecki, J. Operational Evaluation of Piston Ring Wear in Large Marine Diesel Engines. J. Polish CIMAC 2012.

(6) Cordtz, R. The Influence of Fuel Sulfur on the Operation of Large Two-Stroke Marine Diesel Engines. Ph.D. Dissertation, Technical University of Denmark, Kgs. Lyngby, 2015. 
(7) Cordtz, R.; Mayer, S.; Eskildsen, S. S.; Schramm, J. Modeling the Condensation of Sulfuric Acid and Water on the Cylinder Liner of a Large Two-Stroke Marine Diesel Engine. J. Mar. Sci. Technol. 2017, $1-10$.

(8) Amblard, C. New Chemistry to Protect against Cold Corrosion in Marine Cylinder Lubricants. J. Japan Inst. Mar. Eng. 2015, 50 (6), 54-62.

(9) Golothan, D. W. Review of the Causes of Cylinder Wear in Marine Diesel Engines. Inst. Mar. Eng. Trans. 1978, 90, 137-163.

(10) Bovington, C. H. Friction, Wear and the Role of Additives in Controlling Them. In Chemistry and Technology of Lubricants; Mortier, R. M., Fox, M. F., Orszulik, S. T., Eds.; Springer Netherlands: Dordrecht, 2010; pp 77-105.

(11) Atkinson, D. Onboard Condition Monitoring of Cold Corrosion in Two-Stroke Marine Diesel Engines. 11th Int. Conf. Cond. Monit. Mach. Fail. Prev. Technol. C. 2014 / MFPT 2014 2014, 5 (2), 17-22.

(12) Marković, I.; Ottewill, R. H.; Cebula, D. J.; Field, I.; Marsh, J. F. Small Angle Neutron Scattering Studies on Non-Aqueous Dispersions of Calcium Carbonate - Part I. The Guinier Approach. Colloid Polym. Sci. 1984, 262 (8), 648-656.

(13) Seddon, E. J.; Friend, C. L.; Roski, J. P. Detergents and Dispersants. In Chemistry and Technology of Lubricants; Mortier, R. M., Fox, M. F., Orszulik, S. T., Eds.; Springer Netherlands: Dordrecht, 2010; pp 213-236.

(14) Bodnarchuk, M. S.; Heyes, D. M.; Breakspear, A.; Chahine, S.; Edwards, S.; Dini, D. Response of Calcium Carbonate Nanoparticles in Hydrophobic Solvent to Pressure, Temperature, and Water. J. Phys. Chem. C 2015, 119 (29), 16879-16888. 
(15) Bodnarchuk, M. S.; Heyes, D. M.; Breakspear, A.; Chahine, S.; Dini, D. A Molecular Dynamics Study of $\mathrm{CaCO}_{3}$ Nanoparticles in a Hydrophobic Solvent with a Stearate Co-Surfactant. Phys. Chem. Chem. Phys. 2015, 17 (20), 13575-13581.

(16) Bodnarchuk, M. S.; Dini, D.; Heyes, D. M.; Breakspear, A.; Chahine, S. Molecular Dynamics Studies of Overbased Detergents on a Water Surface. Langmuir 2017, 33 (29), 7263-7270.

(17) Jakobsen, S. B. Service Experience of MAN B\&W Two Stroke Diesel Engines. In 28th CIMAC World Congress; Helsinki, 2016.

(18) Jacobsen, D. M. S.; Pedersen, J. M.; Svensson, J.; Mayer, S. Cylinder Lube Oil Experiences and New Development for the MAN B\&W Two-Stroke Engines. In 28th CIMAC World Congress; Helsinki, 2016.

(19) Christensen, O. Cylinder Lubrication of Two-Stroke Crosshead Marine Diesel Engines. Wärtsilä Tech. J. 2010, 39-48.

(20) Wu, R. C.; Papadopoulos, K. D.; Campbell, C. B. Visualization Test for Neutralization of Acids by Marine Cylinder Lubricants. AIChE J. 1999, 45 (9), 2011-2017.

(21) Wu, R. C.; Papadopoulos, K. D.; Campbell, C. B. Acid-Neutralizing of Marine Cylinder Lubricants: Measurements and Effects of Dispersants. AIChE J. 2000, 46 (7), 1471-1477.

(22) Wu, R. C.; Campbell, C. B.; Papadopoulos, K. D. Acid-Neutralizing of Marine Cylinder Lubricants: Effects of Nonionic Surfactants. Ind. Eng. Chem. Res. 2000, 39 (10), 3926-3931.

(23) Fu, J.; Lu, Y.; Campbell, C. B.; Papadopoulos, K. D. Optical Microscopy inside a Heating Capillary. Ind. Eng. Chem. Res. 2005, 44 (5), 1199-1203.

(24) Fu, J.; Lu, Y.; Campbell, C. B.; Papadopoulos, K. D. Temperature and Acid Droplet Size Effects in Acid Neutralization of Marine Cylinder Lubricants. Tribol. Lett. 2006, 22 (3), 221-225. 
(25) Fu, J.; Lu, Y.; Campbell, C. B.; Papadopoulos, K. D. Acid Neutralization by Marine Cylinder Lubricants Inside a Heating Capillary: Strong/Weak-Stick Collision Mechanisms. Ind. Eng. Chem. Res. 2006, 45 (16), 5619-5627.

(26) Fu, J.; Papadopoulos, K. D.; Lu, Y.; Campbell, C. B. Ostwald Ripening: A Decisive Cause of Cylinder Corrosive Wear. Tribol. Lett. 2007, 27 (1), 21-24.

(27) Garcia-Bermudes, M.; Rausa, R.; Papadopoulos, K. Vertically-Oriented-Capillary Video-Microscopy: Drops Levitated by a (Reacting) Fluid. Ind. Eng. Chem. Res. 2011, 50 (24), 14142-14147.

(28) Garcia-Bermudes, M.; Rausa, R.; Papadopoulos, K. Formation of Colloidal Shells on Acidic Droplets Undergoing Neutralization in Marine Diesel Engine Cylinder Oils. Tribol. Lett. 2013, 51 (1), 85-92.

(29) Duan, Y.; Rausa, R.; Zhao, Q.; Papadopoulos, K. D. Neutralization Mechanism of Acetic Acid by Overbased Colloidal Nanoparticles. Tribol. Lett. 2016, 64 (8), 1-11.

(30) Hone, D. C.; Robinson, B. H.; Steytler, D. C.; Glyde, R. W.; Cleverley, J. A. Acid-Base Chemistry in High-Performance Lubricating Oils. Can. J. Chem. 1999, 77, 842-848.

(31) Hone, D. C.; Robinson, B. H.; Steytler, D. C.; Glyde, R. W.; Galsworthy, J. R. Mechanism of Acid Neutralization by Overbased Colloidal Additives in Hydrocarbon Media. Langmuir 2000, 16 (2), 340 346.

(32) Hone, D.; Robinson, B.; Galsworthy, J.; Glyde, R. Colloidal Chemistry of Lubricating Oils. In Reactions And Synthesis In Surfactant Systems; Texter, J., Ed.; Surfactant Science; CRC Press, 2001; pp 385-394.

(33) Hosonuma, K.; Tamura, K. Acid Neutralization of Overbased Detergents (Part 1) Neutralization in the Test Methods of ASTM Base Number. J. Japan Pet. Inst. 1984, 27 (2), 101-107.

(34) Hosonuma, K.; Tamura, K. Acid Neutralization of Overbased Detergents (Part 2) Neutralization with 
Sulfuric Acid Emulsion. J. Japan Pet. Inst. 1984, 27 (2), 108-113.

(35) Roman, J.-P. New Method of Measurement in Thin Film of the Neutralization of Marine Lubricants for Low-Speed and Medium-Speed Diesel Engines. In CIMAC Congress 1998, Copenhagen; Copenhagen, 1998; pp 913-926.

(36) Akiyama, K.; Masunaga, K.; Kado, K.; Yoshioka, T. Cylinder Wear Mechanism in an EGR-Equipped Diesel Engine and Wear Protection by the Engine Oil. Paper 872158. SAE Int. 1987, 1-7.

(37) Roman, J.-P.; Foin, C.; Hosonuma, K.; Naganuma, N. Study of the Impact of Marine Lubricants Additive Chemistry on Adhesive Wear, Scuffing and Corrosive Wear - Relationship between Neutralization Speed Measured by NAMO and Corrosive Wear. In CIMAC Congress; Hamburg, 2001; pp 1284-1298.

(38) Lejre, K. H.; Kiil, S.; Glarborg, P.; Christensen, H.; Mayer, S. Reaction of Sulfuric Acid in Lube Oil: Implications for Large Two-Stroke Diesel Engines. In Proceedings of the ASME 2017 Internal Combustion Engine Division Fall Technical Conference; ASME: Seattle, United States, 2017; Vol. 1, pp $1-10$.

(39) Schramm, J.; Henningsen, S.; Sorenson, S. C. Modelling of Corrosion of Cylinder Liner in Diesel Engines Caused by Sulphur in the Diesel Fuel. In SAE Technical Paper; SAE International, 1994; pp 110.

(40) van Helden, A. K. A Physico-Chemical Model of Corrosive Wear in Low Speed Diesel Engines, Report D-9. 1987, pp 1-16.

(41) van Helden, A. K.; Valentijn, M. C.; van Doornt, H. M. J. Corrosive Wear in Crosshead Diesel Engines. Tribol. Int. 1989, 22 (3), 189-193.

(42) ASTM International. ASTM 2896-11. Standard Test Method for Base Number of Petroleum Products by 
Potentiometric Perchloric Acid Titration. 2011.

(43) Kiil, S. Experimental and Theoretical Investigations of Wet Flue Gas Desulphurisation. Ph.D. Dissertation, Technical University of Denmark, Kgs. Lyngby, 1998.

(44) Laidler, K. J. Chemical Kinetics; Harper \& Row: New York, 1987.

(45) Goodwin, J. W. Colloids and Interfaces with Surfactants and Polymers; John Wiley \& Sons, Ltd: Chichester, UK, 2009.

(46) Kontogeorgis, G. M.; Kiil, S. Introduction to Applied Colloid and Surface Chemistry; John Wiley \& Sons, Ltd: Chichester, UK, 2016.

(47) Sautermeister, F. A.; Priest, M. Physical and Chemical Impact of Sulphuric Acid on Cylinder Lubrication for Large 2-Stroke Marine Diesel Engines. Tribol. Lett. 2012, 47 (2), 261-271.

(48) Sautermeister, F. A.; Priest, M.; Lee, P. M.; Fox, M. F. Impact of Sulphuric Acid on Cylinder Lubrication for Large 2-Stroke Marine Diesel Engines: Contact Angle, Interfacial Tension and Chemical Interaction. Tribol. Int. 2013, 59, 47-56.

(49) Hudson, L. K.; Eastoe, J.; Dowding, P. J. Nanotechnology in Action: Overbased Nanodetergents as Lubricant Oil Additives. Adv. Colloid Interface Sci. 2006, 123-126 (SPEC. ISS.), 425-431.

(50) Roman, J.-P.; Hoornaert, P.; Faure, D.; Biver, C.; Jacquet, F.; Martin, J.-M. Formation and Structure of Carbonate Particles in Reverse Microemulsions. J. Colloid Interface Sci. 1991, 144 (2), 324-339.

(51) Marković, I.; Ottewill, R. H. Small Angle Neutron Scattering Studies on Non-Aqueous Dispersions of Calcium Carbonate. Part III. Concentrated Dispersions. Colloid Polym. Sci. 1986, 264 (5), 454-462.

(52) Marković, I.; Ottewill, R. H. Small Angle Neutron Scattering Studies on Nonaqueous Dispersions of Calcium Carbonate Part 2. Determination of the Form Factor for Concentric Spheres. Colloid Polym. Sci. 
1986, 264 (1), 65-76.

(53) Duan, Y.; Rausa, R.; Fiaschi, P.; Papadopoulos, K. D. Neutralization of Acetic Acid by Automobile Motor Oil. Tribol. Int. 2016, 98, 94-99.

(54) John R. Rumble. CRC Handbook of Chemistry and Physics http://hbcponline.com (accessed May 1, 2018).

(55) Perry, R. H. Perry's Chemical Engineers' Handbook, 7th ed.; Green, D. W., Maloney, J. O., Eds.; McGraw-Hill: New York, 1997.

(56) Karvounis, N.; Pang, K. M.; Mayer, S.; Walther, J. H. Numerical Simulation of Condensation of Sulfuric Acid and Water in a Large Two-Stroke Marine Diesel Engine. Appl. Energy 2018, 211, 1009-1020.

(57) CIMAC Working Group 8 "Marine Lubricants.” CIMAC Recommendation 31: The Lubrication of TwoStroke Crosshead Diesel Engines. 2017.

(58) Christiansen, J.; Klit, P.; Volund, A.; Hwang, J.-H. Calculation of Oil Film Thickness from Damping Coefficients for a Piston Ring in an Internal Combustion Engine. In Proceedings of the International Conference BALTTRIB'2007; Kaunas, 2007; pp 162-167.

(59) Doyen, V.; Drijfholt, R. K.; Delvigne, T. PAPER NO .: 61 Advanced Applied Research Unravelling the Fundamentals of 2-Stroke Engine Cylinder Lubrication - an Innovative on-Line Measurement Method Based on the Use of Radioactive Tracers-. CIMAC Congr. 2007, Vienna 2007.

(60) Stott, F. H.; Macdonald, A. G. The Influence of Acid Strength on the Corrosive Wear of Grey Cast Irons in Oil-Sulphuric Acid Mixtures. Wear 1988, 122 (3), 343-361.

(61) Macdonald, A. G.; Stott, F. H. The Corrosive Wear of Cast Iron in Oil-Sulphuric Acid Mixtures. Corros. Sci. 1988, 28 (5), 485-501. 
(62) Cordtz, R.; Schramm, J.; Andreasen, A.; Eskildsen, S. S.; Mayer, S. Modeling the Distribution of Sulfur Compounds in a Large Two Stroke Diesel Engine. Energy Fuels 2013, 27 (3), 1652-1660.

(63) Hammett, J. Utilising the Latest Findings Engine Oil Stress from Field \& Laboratory Engine Testing. J. JIME 2014, 49 (3), 6-13.

(64) Pang, K. M.; Karvounis, N.; Walther, J. H.; Schramm, J.; Glarborg, P.; Mayer, S. Modelling of Temporal and Spatial Evolution of Sulphur Oxides and Sulphuric Acid under Large, Two-Stroke Marine Enginelike Conditions Using Integrated CFD-Chemical Kinetics. Appl. Energy 2017, 193, 60-73. 


\section{List of figure captions}

Figure 1. Selected segment of infrared spectra showing the $\mathrm{CaCO}_{3}$ and $\mathrm{CaSO}_{4}$ peaks of four different lube oil blends with different amounts of added $\mathrm{H}_{2} \mathrm{SO}_{4}$, giving $\mathrm{CaCO}_{3}$ concentrations in the range 98.6-21.5 $\mathrm{BN}$. When more $\mathrm{H}_{2} \mathrm{SO}_{4}$ is added, the $\mathrm{CaCO}_{3}$ peak decreases and the $\mathrm{CaSO}_{4}$ increases. The spectrum of the 98.6 $\mathrm{BN}$ lube oil is a fresh lube oil without the addition of $\mathrm{H}_{2} \mathrm{SO}_{4}$.

Figure 2. Neutralization mechanism between an acid droplet and $\mathrm{CaCO}_{3}$ reverse micelle (adapted from Wu et al. $\left.{ }^{21}\right)$.

Figure 3. Results from the $\mathrm{NaOH}-\mathrm{H}_{2} \mathrm{SO}_{4}$-lube oil batch reactor experiments, showing the accumulative percentage conversions of $\mathrm{NaOH}$ and $\mathrm{CaCO}_{3}$ at two different $\mathrm{Ca} / \mathrm{S}$. Error bars represent two times the sample standard deviation based on two repetitions.

Figure 4. Effect of varying the stirrer speed $(\mathrm{N})$ on the $\mathrm{CaCO}_{3}$ conversion in the lube oil. Error bars represent two times the sample standard deviation. Experimental conditions are: stirrer speed $=120-1200 \mathrm{rpm}$, inlet $\mathrm{H}_{2} \mathrm{SO}_{4}$ concentration $=96.5 \mathrm{wt} . \%$, and residence time (for Fast Analysis) $=2.1-2.8 \mathrm{~min}$ (see Table $\mathrm{S} 1 \mathrm{in}$ Supporting Information for more information on each experimental number).

Figure 5. Effect of varying $\mathrm{Ca} / \mathrm{S}$ molar ratio on the $\mathrm{CaCO}_{3}$ conversion in the lube oil. Error bars represent two times the sample standard deviation. Experimental conditions are: stirrer speed $=1200 \mathrm{rpm}$, inlet $\mathrm{H}_{2} \mathrm{SO}_{4}$ concentration $=96.5 \mathrm{wt} . \%$, and residence time $($ for Fast Analysis) $=2.1-3.5$ min (see Table S1 in Supporting Information for more information on each experimental number).

Figure 6. Effect of varying the $\mathrm{Ca} / \mathrm{S}$ molar ratio on the $\mathrm{H}_{2} \mathrm{SO}_{4}$ conversion. Error bars represent two times the sample standard deviation. Experimental conditions as in Figure 5.

Figure 7. Schematic illustration of the neutralization of $\mathrm{H}_{2} \mathrm{SO}_{4}$ droplets in a lube oil by $\mathrm{CaCO}_{3}$ reverse micelles under mixed flow reactor conditions. Lube oil volume and inlet and outlet conditions are indicated in the 
figure.

Figure 8. Model simulations showing conversion of (a) $\mathrm{CaCO}_{3}$ reverse micelles and (b) $\mathrm{H}_{2} \mathrm{SO}_{4}$ droplets as a function of $\mathrm{Ca} / \mathrm{S}$ by using a micelle diffusion-controlled reaction rate constant and an adsorptioncontrolled reaction rate constant at three values of $\mathrm{H}_{2} \mathrm{SO}_{4}$ radius, $\mathrm{R}_{\mathrm{SA}}$. Circles represent $\mathrm{MFR}$ experimental data from Figs. 5 and 6. Model parameters are presented in Table 1.

Figure 9. Illustration of lube oil dosage, $\mathrm{H}_{2} \mathrm{SO}_{4}$ droplet condensation, and mixing in an engine: (a) when the piston approaches top dead center (TDC), fresh lube oil is dosed onto the piston ring pack ${ }^{57}$ (the injection frequency of fresh lube oil is typically once every third to eighth engine revolution), (b) $\mathrm{H}_{2} \mathrm{SO}_{4}$ condenses onto the lube oil film when the piston moves towards the bottom dead center (BDC), (c) the piston moves towards TDC again, contributing to a well-mixed lube oil film where the $\mathrm{H}_{2} \mathrm{SO}_{4}$ droplets are emulsified in the lube oil, and (d) horizontal close-up of a piston ring-lube oil film, where a moving front may develop where the lube oil and $\mathrm{H}_{2} \mathrm{SO}_{4}$ droplets are effectively mixed.

Figure 10. Model simulations showing conversion of (a) $\mathrm{CaCO}_{3}$ reverse micelles and (b) $\mathrm{H}_{2} \mathrm{SO}_{4}$ droplets as a function of $\mathrm{Ca} / \mathrm{S}$ at three values of $\mathrm{k}_{\mathrm{ads}}$ and $\mathrm{R}_{\mathrm{SA}}$, respectively. Model parameters are: $\mathrm{T}=423 \mathrm{~K}, \tau=0.5$ $\mathrm{s}, \mathrm{f}_{\mathrm{L}, \mathrm{oil}, \mathrm{w}}=0.089 \mathrm{~kg} \mathrm{~kg}^{-1}(100 \mathrm{BN}), \mathrm{C}_{\mathrm{SA}, \mathrm{d}}=18 \cdot 10^{3} \mathrm{~mol} \mathrm{~m}^{-3}$, as well as those in Table 1.

Figure 11. Model simulations showing conversion of (a) $\mathrm{CaCO}_{3}$ reverse micelles and (b) $\mathrm{H}_{2} \mathrm{SO}_{4}$ droplets as a function of $\mathrm{Ca} / \mathrm{S}$ at three values of the base number of the lube oil. Model parameters are: $\mathrm{R}_{\mathrm{SA}}=0.5 \mu \mathrm{m}$, $\mathrm{T}=423 \mathrm{~K}, \tau=0.5 \mathrm{~s}, \mathrm{C}_{\mathrm{SA}, \mathrm{d}}=18 \cdot 10^{3} \mathrm{~mol} \mathrm{~m}^{-3}$, as well as those in Table 1.

Figure 12. Model simulations showing conversion of (a) $\mathrm{CaCO}_{3}$ reverse micelles and (b) $\mathrm{H}_{2} \mathrm{SO}_{4}$ droplets as a function of $\mathrm{Ca} / \mathrm{S}$ at three values of $\mathrm{H}_{2} \mathrm{SO}_{4}$ droplet concentration. Model parameters are: $\mathrm{R}_{\mathrm{SA}}=0.5 \mu \mathrm{m}, \mathrm{T}$ $=423 \mathrm{~K}, \tau=0.5 \mathrm{~s}, \mathrm{f}_{\mathrm{L}, \mathrm{oil}, \mathrm{w}}=0.089 \mathrm{~kg} \mathrm{~kg}^{-1}(100 \mathrm{BN})$, as well as those in Table 1.

Figure 13. Model simulations showing conversion of (a) $\mathrm{CaCO}_{3}$ reverse micelles and (b) $\mathrm{H}_{2} \mathrm{SO}_{4}$ droplets as a 
function of Ca/S at three values of lube oil film residence time. Model parameters are: $\mathrm{R}_{\mathrm{SA}}=0.5 \mu \mathrm{m}, \mathrm{T}=$ $423 \mathrm{~K}, \mathrm{f}_{\mathrm{L}, \mathrm{oil}, \mathrm{w}}=0.089 \mathrm{~kg} \mathrm{~kg}^{-1}(100 \mathrm{BN}), \mathrm{C}_{\mathrm{SA}, \mathrm{d}}=18 \cdot 10^{3} \mathrm{~mol} \mathrm{~m}^{-3}$, as well as those in Table 1.

Figure 14. Model simulations showing conversion of (a) $\mathrm{CaCO}_{3}$ reverse micelles and (b) $\mathrm{H}_{2} \mathrm{SO}_{4}$ droplets as a function of residence time at three values of $\mathrm{Ca} / \mathrm{S}$. Model parameters are: $\mathrm{R}_{\mathrm{SA}}=0.5 \mu \mathrm{m}, \mathrm{T}=423 \mathrm{~K}$, $\mathrm{f}_{\mathrm{L}, \mathrm{oil}, \mathrm{w}}=0.089 \mathrm{~kg} \mathrm{~kg}^{-1}(100 \mathrm{BN}), \mathrm{C}_{\mathrm{SA}, \mathrm{d}}=18 \cdot 10^{3} \mathrm{~mol} \mathrm{~m}^{-3}$, as well as those in Table 1.

Figure 15. Model simulations showing conversion of (a) $\mathrm{CaCO}_{3}$ reverse micelles and (b) $\mathrm{H}_{2} \mathrm{SO}_{4}$ droplets as a function of $\mathrm{Ca} / \mathrm{S}$ at varying temperature between $373 \mathrm{~K}$ and $533 \mathrm{~K}$. Model parameters are: $\mathrm{R}_{\mathrm{SA}}=0.5 \mu \mathrm{m}$, $\tau=0.5 \mathrm{~s}, \mathrm{f}_{\mathrm{L}, \mathrm{oil}, \mathrm{w}}=0.089 \mathrm{~kg} \mathrm{~kg}^{-1}(100 \mathrm{BN}), \mathrm{C}_{\mathrm{SA}, \mathrm{d}}=18 \cdot 10^{3} \mathrm{~mol} \mathrm{~m}^{-3}$, as well as those in Table 1 . The vertical dotted line represents $\mathrm{Ca} / \mathrm{S}=1$.

Figure 16. Model simulations showing the average concentration of $\mathrm{H}_{2} \mathrm{SO}_{4}$ in the lube oil film as a function of $\mathrm{Ca} / \mathrm{S}$ at varying temperatures between $373 \mathrm{~K}$ and $533 \mathrm{~K}$. Model parameters are: $\mathrm{R}_{\mathrm{SA}}=0.5 \mu \mathrm{m}, \tau=0.5 \mathrm{~s}$, $\mathrm{f}_{\mathrm{L}, \mathrm{oil}, \mathrm{w}}=0.089 \mathrm{~kg} \mathrm{~kg}^{-1}(100 \mathrm{BN}), \mathrm{C}_{\mathrm{SA}, \mathrm{d}}=18 \cdot 10^{3} \mathrm{~mol} \mathrm{~m}^{-3}$, and the ones presented in Table 1. The vertical dotted line represents $\mathrm{Ca} / \mathrm{S}=1$. 


\section{For Table of Contents Only}

2

3

4

5

6

7

8

9

10

11

12

13

14

15

16

17

18

19

20

21

22

23

24

25

26

27

28

29

30

31

32

33

34

35

36

37

38

39

40

41

42

43

44

45

46

47

48

49

50

51

52

53

54

55

56

57

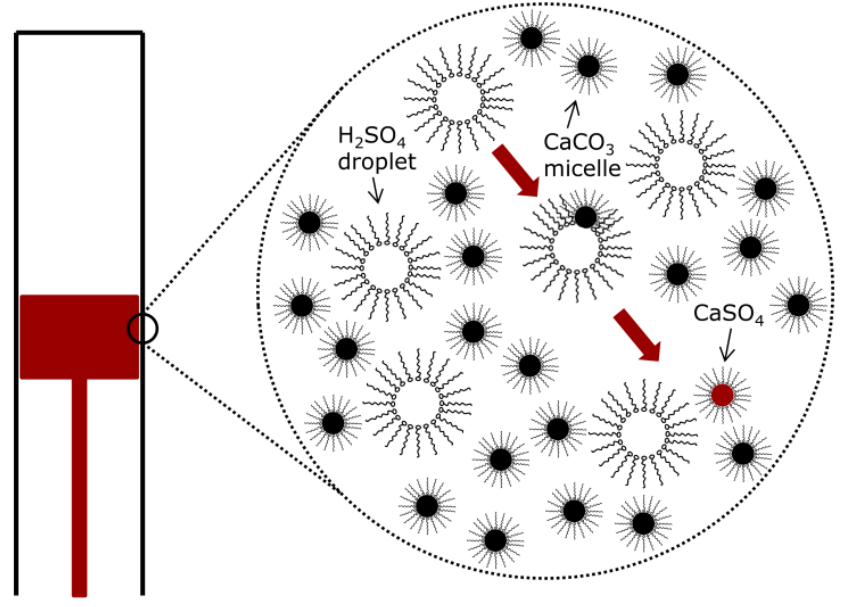

